\title{
Short-Term Efficacy of Biologic Therapies in Moderate- to-Severe Plaque Psoriasis: A Systematic Literature Review and an Enhanced Multinomial Network Meta- Analysis
}

\author{
Kyle Fahrbach • Grammati Sarri • David M. Phillippo • \\ Binod Neupane $\cdot$ Samantha E. Martel $\cdot$ Sandeep Kiri $\cdot$ Kristian Reich
}

Received: July 22, 2021 / Accepted: August 19, 2021 / Published online: September 22, 2021

(C) The Author(s) 2021

\section{ABSTRACT}

Introduction: Many targeted, systemic therapies have been developed for treatment of moderate-to-severe psoriasis (PsO). A network meta-analysis (NMA) allows for comparison between treatments not directly compared in randomized controlled trials (RCT). This study's objective was to compare the short-term (10-16 weeks) clinical efficacy according to the Psoriasis Area and Severity Index (PASI) among

Supplementary Information The online version contains supplementary material available at https:// doi.org/10.1007/s13555-021-00602-z.

K. Fahrbach $(\varangle) \cdot$ B. Neupane · S. E. Martel Evidera (Evidence Synthesis), 500 Totten Pond Road, Fifth Floor, Waltham, MA 02451, USA e-mail: Kyle.fahrbach@evidera.com

G. Sarri

Evidera (Evidence Synthesis) The Ark, 201 Talgarth Rd., Hammersmith, London W6 8BJ, UK

\section{M. Phillippo}

Bristol Medical School (Population Health Sciences), University of Bristol, Bristol, UK

S. Kiri

UCB Pharma Ltd, Slough, UK

K. Reich

Translational Research in Inflammatory Skin Diseases, Institute for Health Services Research in Dermatology and Nursing, University Medical Center Hamburg-Eppendorf and Skinflammation ${ }^{\circledR}$ Center, Hamburg, Germany approved biologic treatments for moderate-tosevere PsO using a novel (enhanced) NMA model.

Methods: A systematic literature review (SLR) of RCTs for patients with moderate-to-severe PsO was conducted. English publications in MEDLINE, Embase, and The Cochrane Library up to March 2019 were searched. An enhanced multinomial Bayesian NMA was performed to simultaneously adjust for baseline risk and utilize the conditional nature of the PASI $(50,75$, 90 , and 100) levels. The model relaxes typical constraints that all treatments must have the same ranks across PASI levels.

Results: The SLR resulted in 319 relevant publications, of which 72 publications from 73 RCTs reporting 10- to 16-week data for at least one PASI response level (30,314 total patients) were included. Interleukin (IL) inhibitors (risankizumab, ixekizumab, brodalumab, secukinumab, and guselkumab) were the best performing treatments for achieving all PASI levels. Etanercept was outperformed by the other subcutaneous tumor necrosis factor $\alpha$ inhibitors. Application of an enhanced NMA model that allowed treatment rankings to differ by PASI level tested the robustness of results of previous NMAs in PsO.

Conclusion: The results of this model confirmed that IL inhibitors are likely the best short-term treatment choices for improving all PASI levels. 
Keywords: Biologic treatment; Efficacy; Network meta-analysis; Psoriasis

\section{Key Summary Points}

\section{Why carry out this study?}

Psoriasis is a chronic inflammatory multisystem disease which has a substantial negative impact on the patients' quality of life and physical and psychologic functioning. Thus, it represents a major economic burden to health systems owing to the disease's chronicity, high prevalence, and disabling effect

The use of biologic therapy has revolutionized the management of moderate-to-severe psoriasis offering healthcare providers and patients with a multitude of highly effective and tolerable treatment options. Nevertheless, head-tohead comparisons between the different biologic treatments in psoriasis are limited. This subsequently leads to uncertainty about their comparative efficacy and limits the clinicians' and patients' ability to make informed decisions about treatment choices. Therefore, we sought to conduct a network meta-analysis (NMA) which allows for comparison between multiple treatments that are not directly compared in a randomized controlled trial (RCT) and produces estimates of treatment effects and rankings that may be used in decision-making

What did the study ask?/What was the hypothesis of the study?

The current study conducted a systematic literature review and an NMA to compare the short-term efficacy at 10-16 weeks (according to the Psoriasis Area and Severity Index [PASI]) among the approved biologic systemic therapies for moderate-to-severe psoriasis

\section{What was learned from the study? \\ What were the study outcomes/conclusions? (data)}

The biologics were associated with better probability of achieving all PASI response levels compared with non-biologics and placebo. All biologics except etanercept had $>80 \%$ probability of achieving PASI50. Interleukin inhibitors (risankizumab $150 \mathrm{mg}$, ixekizumab $80 \mathrm{mg}$, brodalumab $210 \mathrm{mg}$, secukinumab 300 $\mathrm{mg}$, and guselkumab $100 \mathrm{mg}$ ) were the best-performing treatments for achieving all levels of short-term PASI $(50,75,90$, and 100). Certolizumab pegol $400 \mathrm{mg}$ and infliximab $5 \mathrm{mg} / \mathrm{kg}$ performed the best among the tumor necrosis factor- $\alpha$ inhibitors

\section{INTRODUCTION}

Psoriasis (PsO) is a chronic, inflammatory, multisystem disease with a prevalence of $2-3 \%$ in Western countries. Its most common (up to $90 \%$ of cases) phenotype, plaque $\mathrm{PsO}$, is characterized by scaly and often itchy red patches [1]. PsO severity can be classified as mild, moderate, or severe, depending on its location, the grading of skin signs, the surface area involved, and the impact on the individual [2]. At least $20 \%$ of patients have disease that involves $>5 \%$ of the body or affects crucial body regions, including the hands, feet, face, or genitals [3]. Severe disease is associated with increased mortality; estimated life expectancy is reduced by 3.5 years in men and 4.4 years in women [4]. Severe PsO also has a substantial impact on quality of life [5], with extensive emotional and psychosocial effects on patients, and represents a major economic burden to health systems owing to the disease's chronicity, high prevalence, and disabling effect. This heavy toll is compounded by the fact that many patients have associated joint disease (psoriatic arthropathy) and comorbidities such as depression, anxiety, and cardiovascular disease [5]. 
Current guidelines recommend oral systemic drugs (e.g., dimethyl fumarate, methotrexate, ciclosporin, and apremilast) and targeted biologic therapies for chronic disease control in patients with moderate-to-severe PsO [6]. During the last 2 decades, different classes of targeted therapies have been developed for $\mathrm{PsO}$ including tumor necrosis factor alpha (TNF- $\alpha$ ) and interleukin (IL) inhibitors. Anti TNF- $\alpha$ treatments include certolizumab pegol (CZP), etanercept, infliximab, and adalimumab. Among the TNF- $\alpha$ inhibitors, CZP has a different structure, as it lacks the immunoglobin $G$ (IgG) fragment crystallizable (Fc). This structural difference results in advantageous solubility and stability and has demonstrated minimal to no placental transfer from mothers to infants due to the absence of the region that binds to the neonatal Fc receptor for IgG (FcRn) [7-9]. The second class of antibodies that has been developed targets pro-inflammatory cytokines, including the IL-12/23p40 antibody (ustekinumab), and, more recently, inhibitors of IL-17A (secukinumab, ixekizumab), IL-17RA (brodalumab), and IL-23p19 (guselkumab, tildrakizumab, risankizumab).

Ample research has been conducted in placebo-controlled trials to evaluate efficacy and safety, but head-to-head comparisons among the biologic treatments are lacking. A network meta-analysis (NMA) allows for comparison between multiple treatments that are not directly compared in a randomized controlled trial (RCT) and produces estimates of treatment effects and rankings that may be used in decision-making [10].

The current study conducted a systematic literature review (SLR) on short-term efficacy among the approved biologic systemic therapies for moderate-to-severe PsO and conducted analyses using a novel enhancement to the standard multinomial NMA model with baseline risk adjustment. This approach relaxes the assumption of a constant probit difference between Psoriasis Area and Severity Index (PASI) cutoffs across treatments, allowing treatments to have different rankings across PASI levels. The analysis focused on the efficacy data at the end of induction treatment (10-16 weeks), specifically, the proportions of patients achieving commonly reported percentage changes with the PASI relative to baseline (PASI50, PASI75, PASI90, and PASI100). Although several efficacy outcomes have been developed in $\mathrm{PsO}$, our analysis selected the use of PASI as it is the most widely reported outcome in PsO trials and has been used as a decision tool for the use of biologics in healthcare decision-making [6]. A high correlation effect has been shown between PASI and other patient-reported outcomes (such as Dermatology Life Quality Index), which demonstrates PASI's role as a primary efficacy end point in PsO trials [11].

\section{METHODS}

\section{SLR Overview}

The SLR followed well-established recommendations of the Cochrane Collaboration [12, 13], and it systematically identified evidence from RCTs (phase II-IV) investigating the short-term efficacy (as measured by all PASI level) of biologic therapies (at dosages approved by the European Medicines Agency) at the end of induction treatment phase (10-16 weeks; Table 1 ) for adults with moderate-tosevere plaque PsO. Non-biologic systemic treatments were included in the NMA to enhance and strengthen the evidence network. The SLR results aligned with the Preferred Reporting Items for Systematic Reviews and Meta-Analyses extension statement for systematic reviews incorporating NMAs of healthcare interventions [14].

MEDLINE, Embase, the Cochrane Central Register of Controlled Trials, the Cochrane Database of Systematic Reviews, and PsycINFO were searched to identify English-language studies conducted on humans and published through March 5, 2019. Searches used a combination of terms and keywords for moderate-to-severe PsO, approved treatments for moderate-to-severe $\mathrm{PsO}$, and study design (RCT; Tables S1-S4). Search terms and strategies were adapted to each database using the appropriate indexing terms. The proceedings of seven relevant conferences (2016 to 2018) were also searched, and searches were validated by cross-checking the reference lists of previous SLRs and NMAs (published between 2016 and 2018) conducted for the same topic to identify any studies not captured by this SLR. 
Table 1 List of drugs and approved dosages

\begin{tabular}{ll}
\hline Drugs & Dosages \\
\hline Systemic biologics & \\
Adalimumab & $40 \mathrm{mg}$ EOW \\
Brodalumab & $210 \mathrm{mg}$ Q2W \\
Certolizumab pegol & $400 \mathrm{mg}$ or $200 \mathrm{mg}$ Q2W \\
Etanercept & $50 \mathrm{mg}$ or $25 \mathrm{mg}$ Q2W \\
Guselkumab & $100 \mathrm{mg}$ Q8W \\
Infliximab & $5 \mathrm{mg} / \mathrm{kg}$ Q8W \\
Ixekizumab & $80 \mathrm{mg}$ Q4W \\
Risankizumab & $150 \mathrm{mg}$ Q12W \\
Secukinumab & $150 \mathrm{mg}$ or $300 \mathrm{mg}$ Q4W \\
Tildrakizumab & $100 \mathrm{mg}$ or $200 \mathrm{mg}$ Q12W \\
Ustekinumab & $45 \mathrm{mg}$ or $90 \mathrm{mg}$ Q12W \\
Systemic non-biologics & \\
Acitretin & $0.4 \mathrm{mg} / \mathrm{kg}$ \\
Apremilast & $30 \mathrm{mg} \mathrm{BID}$ \\
Cyclosporine & $2.5-5 \mathrm{mg} / \mathrm{kg} / \mathrm{day}$ \\
Dimethyl fumarate & $720 \mathrm{mg}$ \\
Methotrexate & $7.5-15 \mathrm{mg}$ \\
\hline BD & \\
\hline
\end{tabular}

$B I D$ twice a day, $E O W$ every other week, $Q 2 W$ every 2 weeks, $Q 4 W$ every 4 weeks, $Q 8 W$ every 8 weeks, $Q 12 W$ every 12 weeks

${ }^{a}$ Ustekinumab was analyzed as $45 \mathrm{mg}$ or $90 \mathrm{mg}$ pooled or $90 \mathrm{mg}$ separate, based on study-level reporting

Abstract and full-text screening was performed by two independent investigators guided by the inclusion and exclusion criteria of the protocol (Table S5). Any discrepancies were resolved by a third, senior investigator. A single investigator extracted data on the study design, types of bias, patient population (including demographic characteristics, comorbidities such as psoriatic arthritis [PsA]), disease duration, prior use of biologics, treatment details, and outcomes of interest for each included RCT. All data were validated by a second, senior investigator using a pre-designed template. The quality of all RCTs was assessed using the Cochrane Risk of Bias Assessment Tool 2.0 [15]. When more than one publication was identified for the same RCT, a single publication (the one with the most complete or most recent information) was selected to avoid double-counting of patients. This article is based on previously conducted studies and does not contain any new studies with human participants or animals performed by any of the authors.

\section{Study Characteristics and NMA Assumptions}

The key assumption in any NMA is that the underlying relative treatment effects (between any two specific treatments, after ignoring the sampling error) are or would be the same in all trial populations [16]. The characteristics of the 
Table 2 Criteria for psoriasis area severity index analysis

\begin{tabular}{|c|c|c|}
\hline PICOS & Inclusion for analysis & Exclusion criteria \\
\hline Population & $\begin{array}{l}\text { Patients with moderate-to-severe } \mathrm{PsO} \text { with or without } \\
\text { comorbid PsA } \\
\text { Studies providing subgroup data for those moderate-to- } \\
\text { severe plaque PsO }\end{array}$ & $\begin{array}{l}\text { Studies in patients primarily with PsA or } \\
\text { with a treatment focus for PsA }\end{array}$ \\
\hline $\begin{array}{l}\text { Intervention/ } \\
\text { Comparator }\end{array}$ & Any protocol-approved intervention and dose & Studies in biosimilar compounds \\
\hline Outcomes & $\begin{array}{l}\text { Any combination of PASI 50, 75, } 90 \text { and/or } 100 \\
\text { presented as discrete/categorical outcomes }\end{array}$ & Mean change in PASI score \\
\hline Time points & $10-16$ weeks [99] & $<10$ weeks or $>16$ weeks \\
\hline Study design & Randomized controlled trials & Open label extension or follow-up studies \\
\hline $\begin{array}{l}\text { Pre-defined } \\
\text { sensitivity } \\
\text { analysis }\end{array}$ & Previous systemic biologic treatment & $\begin{array}{l}\text { Other subgroups (i.e., patient demographics, } \\
\text { comorbid conditions) }\end{array}$ \\
\hline Other restrictions & $\begin{array}{l}\text { Randomized controlled trials with sample size }>30 \\
\text { patients }\end{array}$ & \\
\hline
\end{tabular}

PASI Psoriasis Area Severity Index, PICOS population, intervention/comparator, outcomes, study design, $P_{s} A$ psoriatic arthritis, $P s O$ psoriasis

included trials were assessed to ensure NMA assumptions were met (Table 2). The presence of potential effect modifiers [17], such as disease duration, baseline PASI, and presence of comorbidities, was assessed to confirm similarity among the included trials. Differences in placebo rates were of interest, since relative treatment effect size in a study may depend on the placebo response; these differences are presented in Fig. 1. To allow for network connectivity and based on clinical expert review, we assumed that small differences in treatment doses and schedule in the non-biologic treatments cyclosporine and methotrexate do not impact relative effects.

\section{Statistical Analysis}

We explored clinical heterogeneity and the performance of NMA models using unadjusted and adjusted models per the National Institute for Health and Care Excellence (NICE) Decision Support Unit recommendations [18-20].
A Bayesian multinomial likelihood (probit link) NMA model was conducted based on the number of patients in four PASI categories: patients achieving 50\%, 75\%, 90\%, and 100\% improvement at 10-16 weeks. The PASI provides a combined assessment of lesion severity and the area affected into one score (ranging from 0 [no disease] to 72 [highest burden of disease]).

Two modifications were made to this NMA model. We added a component for baseline risk, per NICE guidelines, as relative effects of drugs in autoimmune diseases are often dependent on baseline risk (i.e., the placebo rate and relative effect of a treatment vs. placebo are likely related) [18]. Given prior research and expert agreement, a baseline risk model was assumed to be the most clinically valid. We decided a priori that, barring convincing evidence to the contrary, the base-case model should include a parameter for baseline risk, given supporting evidence in recent publications and how common the adoption of placebo-adjusted NMA 


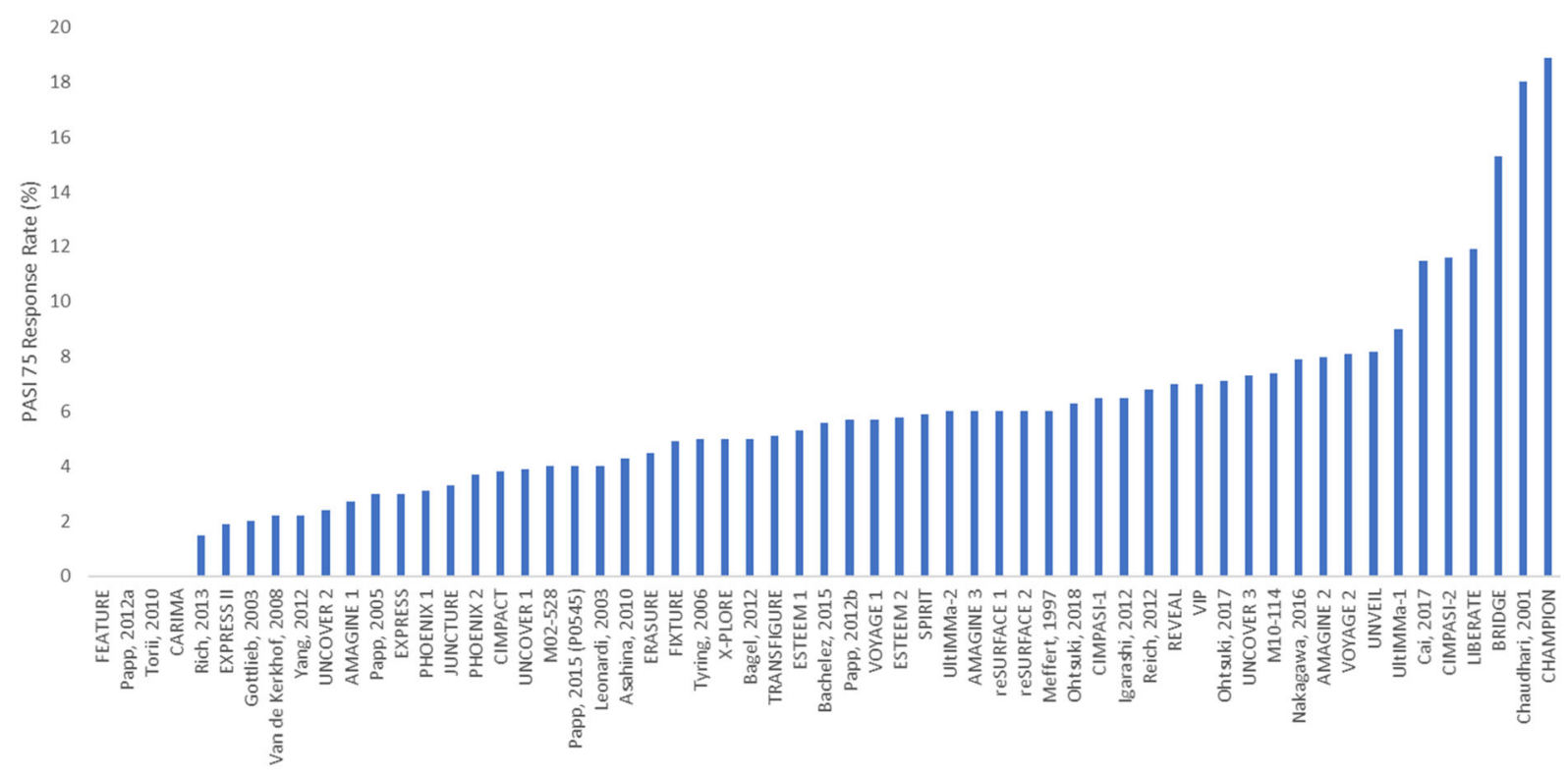

NA, trial name not applicable; PASI, Psoriasis Area and Severity Index

Fig. 1 Placebo response rates across the trials for PASI75

models is in PsO comparative evidence synthesis [17, 21, 22]. Models without baseline risk were explored in a sensitivity analysis.

The other modification allowed flexibility around the key assumption in the standard multinomial model (i.e., that each treatment has the same probit difference between PASI cutoffs PASI cutoffs-e.g., in probit terms, each treatment has the same conditional difficulty to advance to PASI90 given achievement on PASI75. This assumption allows 'borrowed strength' across PASI cutoffs, but it also leads to the effect that all treatments will have the same treatment rank for each PASI level. Our modification added a random-effects (RE) component that allowed each treatments' increase in difficulty to the next-highest PASI cutoff to vary around a common mean, thus allowing 'borrowed strength' across PASI cutoffs but also allowing treatments to have different efficacies (and thus different rankings) for different levels of PASI. This enhanced model is referred to as the 'REZ' model because it adds an RE component to the parameter $z$, which reflects the difficulty to go from one PASI cutoff to the next. More details, including exemplar model code, are provided in the Supporting Information.
All analyses were run with fixed-effects (FE) and RE modeling for relative treatment effects, for a total of eight scenarios (models) tested (crossing $\mathrm{FE} / \mathrm{RE}$ for treatment effects with inclusion/exclusion of baseline risk and standard vs. REZ modeling). Binomial analyses with a logit link were also conducted for all four PASI responses, as sensitivity analyses. However, in these binomial analyses (especially of PASI50 or PASI100), some interventions were not compared because of lack of trial data.

In all Bayesian NMAs, non-informative priors were used for all non-RE parameters. In the RE models, a Uniform $(0,1)$ prior was used for $\tau$ (the square root of the treatment effect variance, i.e., the heterogeneity standard deviation [SD]). In the REZ model, a Uniform $(0,0.5)$ prior was used for $\sigma_{z T}$ (the square root SD around the value between probit cutoffs). Sensitivity analyses around these values (Uniform $(0,0.25)$ and Uniform $(0,1))$ were tested for any sensitivity to the choice of prior, but none were found (likely due to the large size of the dataset).

All Bayesian analyses were carried out with Markov chain Monte Carlo simulations, with 50,000 discarded burn-in iterations followed by 50,000 iterations for parameter estimation. 
Convergence was confirmed by evaluating the three-chain, Brooks-Gelman-Rubin plots $[23,24]$ and values of $\widehat{R}$ (potential scale reduction factor [24], considered converged if $\widehat{R}<$ 1.05 for all parameters being estimated) as well as the ratios of Monte Carlo error to the SDs of the posteriors. The median and (2.5th and 97.5th) percentiles of the posterior samples for each effect were used as an estimate of the effect (e.g., probit differences between treatments) and its 95\% credible interval (CrI). These posterior samples were also used to obtain the rank probability of a treatment being the best, the probability of a treatment being better than each comparator, and each treatment's surface under the cumulative ranking curve index [25]. A separate natural history model [20], using the most recent, robust placebo data (placebo arms with $n \geq 50$ patients in studies published 2013 or later) to ensure that extrapolated response proportions reflect current practice [26-87] estimated an 'anchor' placebo rate for PASI50 of $17.9 \%$, allowing the models to estimate PASI probabilities for each treatment for each PASI level relative to this anchor.

Goodness of fit of the eight analytic models was compared using the posterior mean residual deviance and deviance information criteria (DIC) [18]. A model with a DIC smaller by $>5$ points is generally considered a better-fitting model [88]. Bayesian NMAs of multinomial models were conducted in JAGS (version 4.3.0), and binomial NMAs were conducted in OpenBUGS (version 3.2.3).

Network inconsistency was assessed using an unrelated mean effect model, as recommended in NICE Technical Support Documents [89]. Residual deviance in each arm in each study was also obtained in the multinomial model (for which average deviance over all PASI responses was computed) to assess absolute fit to the data. Arm-level deviances from different models were investigated, as badly fitting data contribute to high heterogeneity, inconsistency, or both in a network; however, no substantive examples of inconsistency or heterogeneity were detected.

Similar analyses were carried out in a subgroup of RCTs in which populations or subpopulations were not previously treated with biologics (100\% of patients who were previously treated or naïve or $\geq 90 \%$ ). There were insufficient studies/subgroup data to conduct analyses on previously treated patients.

\section{RESULTS}

\section{SLR Search Results}

The electronic database searches yielded 4135 publications, and 78 references were retrieved from the review of conference proceedings. After screening, 319 publications met the inclusion criteria for the broad SLR reporting clinical outcomes of treatments for moderateto-severe plaque PsO. Among these, 72 publications (across 73 RCTs) covering 30,314 patients reported results for at least one PASI level $(50,75,90$, and or 100$)$ at 10 to 16 weeks and were included in the base case NMA. Figure 2 summarizes the flow of included studies in the SLR and NMA, and Fig. 3 presents the NMA network diagram.

\section{Study and Patient Characteristics}

Eight of the 73 included RCTs were phase II, 2 were phase II/III, 51 were phase III or IV, and 12 did not report their phases. All had similar inclusion/exclusion criteria and definitions of $\mathrm{PsO}$ severity. The proportion of patients with comorbid PsA (in mixed populations) ranged from 2.4 to $55.8 \%$ (trials were excluded if all patients had comorbid PsA). Sample sizes ranged from 40 to 1306 patients, with most studies analyzing at least 100 patients. Details on patient characteristics are presented in Table 3. Sixty-three trials were deemed to have low risk of bias, seven were rated as having some concerns, and three had a high risk of bias. The main driver of bias was missing outcome data for some patients (i.e., lack of intent-to-treat analyses). Studies had wide variation in reported placebo rates, justifying the baseline-risk adjustment model to the extent that placebo rates are related to relative effect vs. placebo (Fig. 1). Summary assessments for each domain 


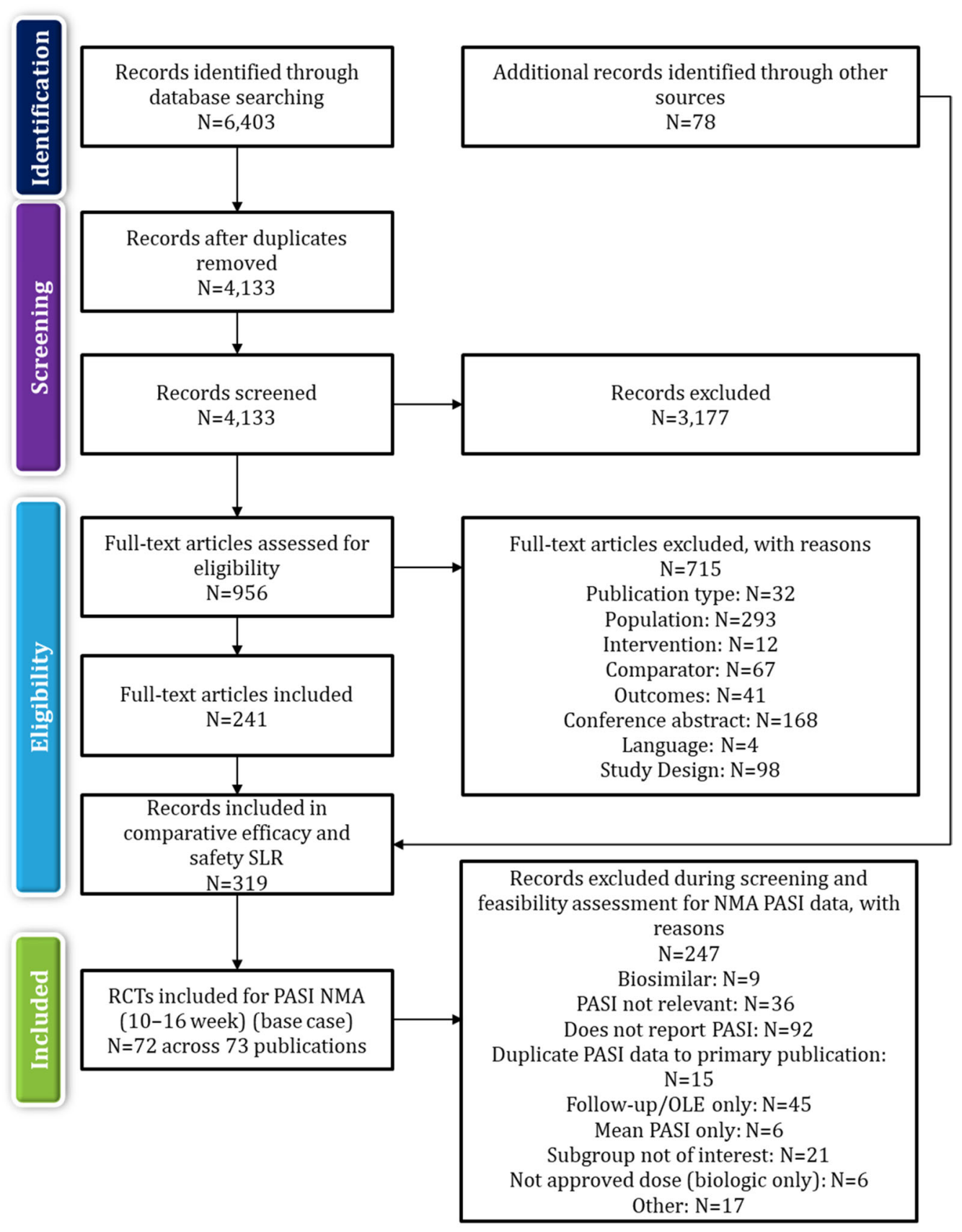

NMA, network meta-analysis; OLE, open-label extension; PASI, Psoriasis Area Severity Index; RCT, randomized controlled trials; SLR, systematic literature review.

Fig. 2 Preferred reporting items for systematic reviews and meta-analysis flow chart 


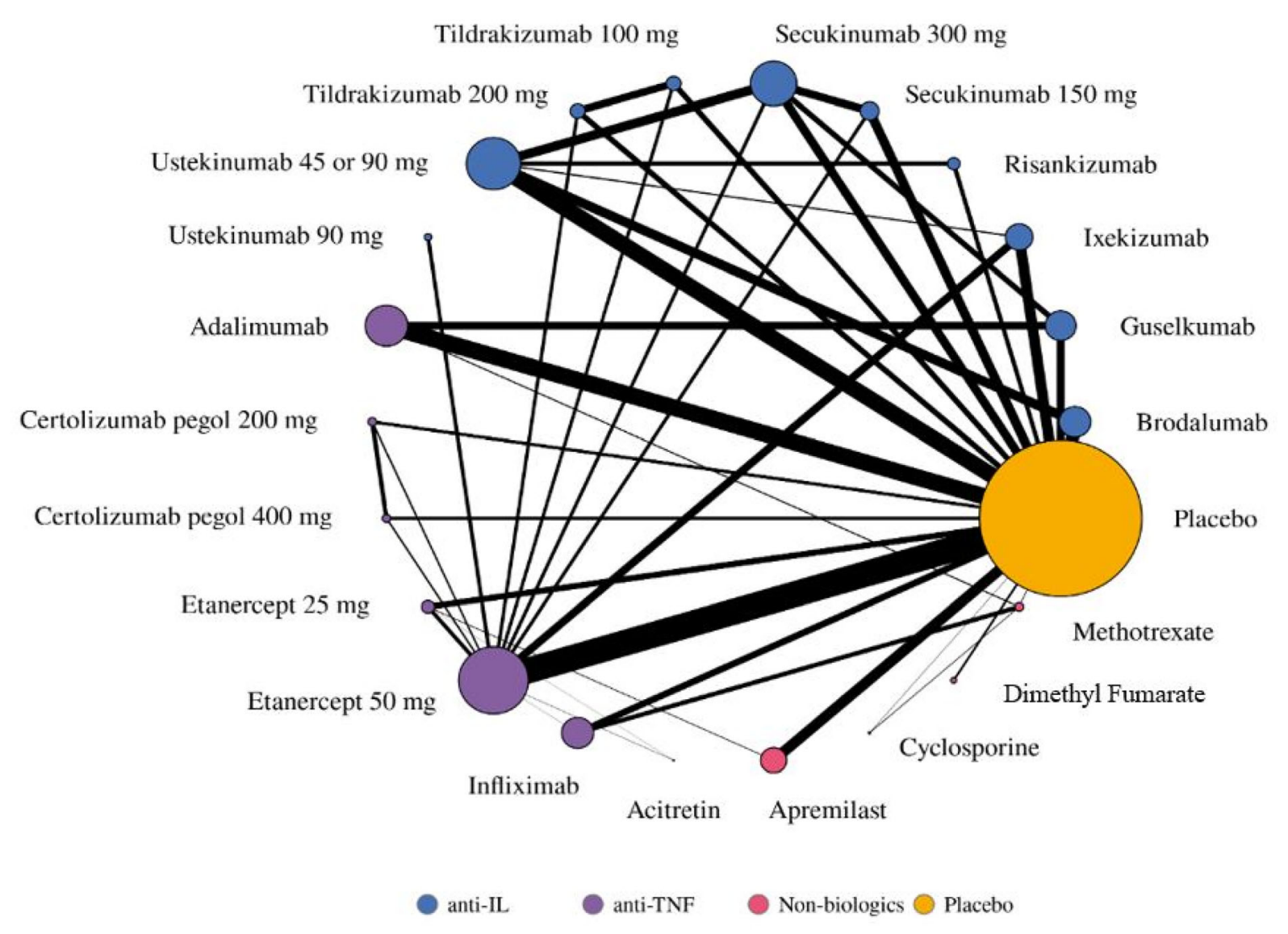

IL, interleukin; TNF, tumor necrosis factor

Fig. 3 PASI (10-16 weeks) NMA network

and the overall risk of bias are summarized in Table S6.

\section{NMA Results}

The most important component for fit was use of REZ modeling versus the standard model. The best-fitting model in terms of DIC was the baseline-unadjusted FE REZ model. While the baseline-risk-adjusted RE REZ model had the smallest mean residual deviance, it involved extra parameters. Given the small difference in DIC, the level of significance for the estimate of the slope $(-0.69$ [95\% CrI: $-0.86,-0.53]$ on the probit scale), and based on clinical recommendations, we maintained our a priori choice of baseline-risk adjusted model (RE REZ) as the base case and the best-fitting baseline- unadjusted FE REZ model was used as a sensitivity analysis (Table 4).

At the end of the induction phase in the base-case model, all treatments considered in the network were more effective than placebo, and all biologic treatments except etanercept were more effective than non-biologics (apremilast, methotrexate, dimethyl fumarate, cyclosporin, or acitretin) at achieving all levels of PASI responses. IL inhibitors (risankizumab $150 \mathrm{mg}$, ixekizumab $80 \mathrm{mg}$ and brodalumab $210 \mathrm{mg}$, secukinumab $300 \mathrm{mg}$, and guselkumab $100 \mathrm{mg}$ ) were the best-performing treatments for achieving all PASI (50, 75, 90, and 100) response in short term. Both doses of etanercept (25 $\mathrm{mg}$ and $50 \mathrm{mg}$ ) had the lowest probabilities of response among the biologics across all PASI response levels (Fig. 4). 


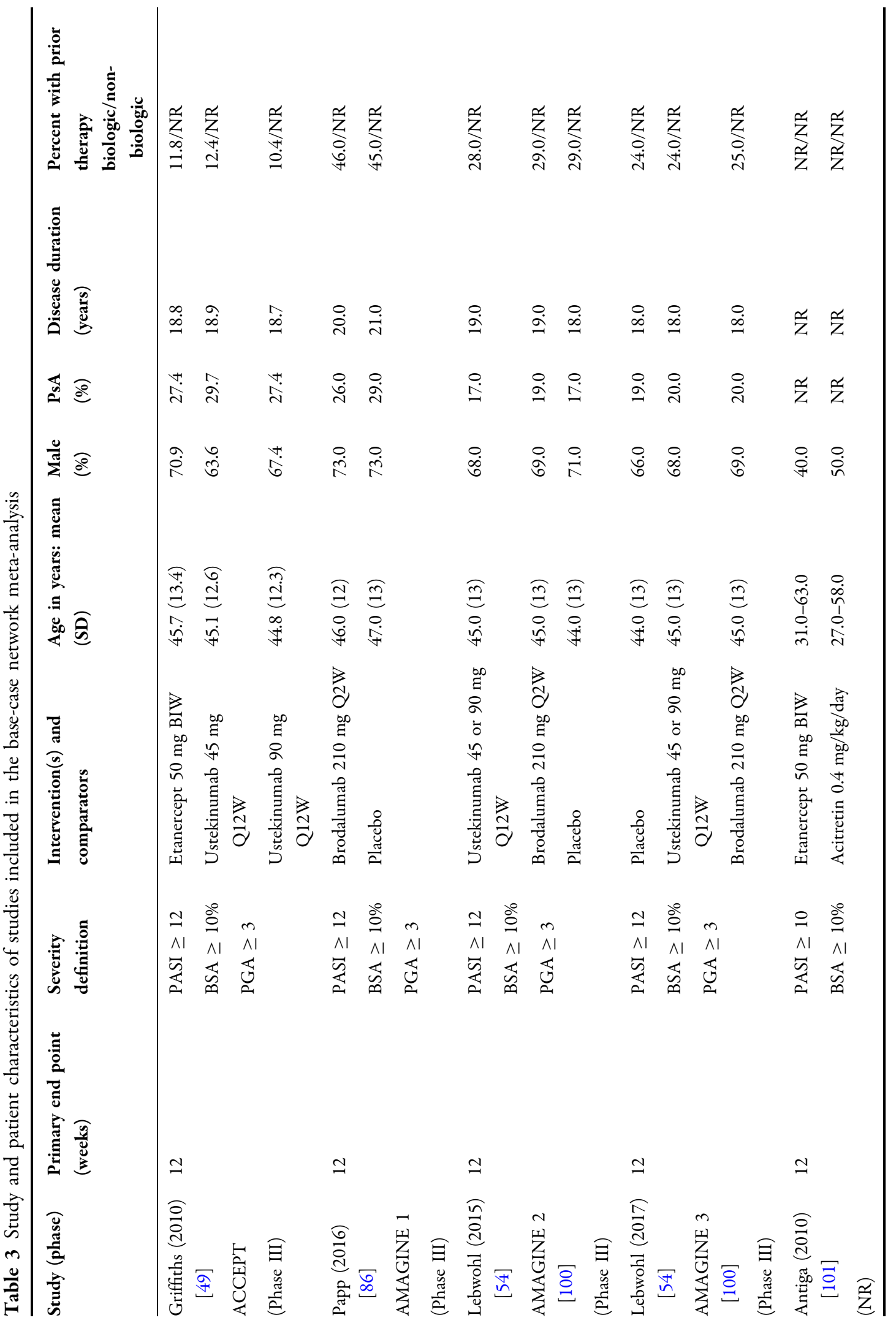




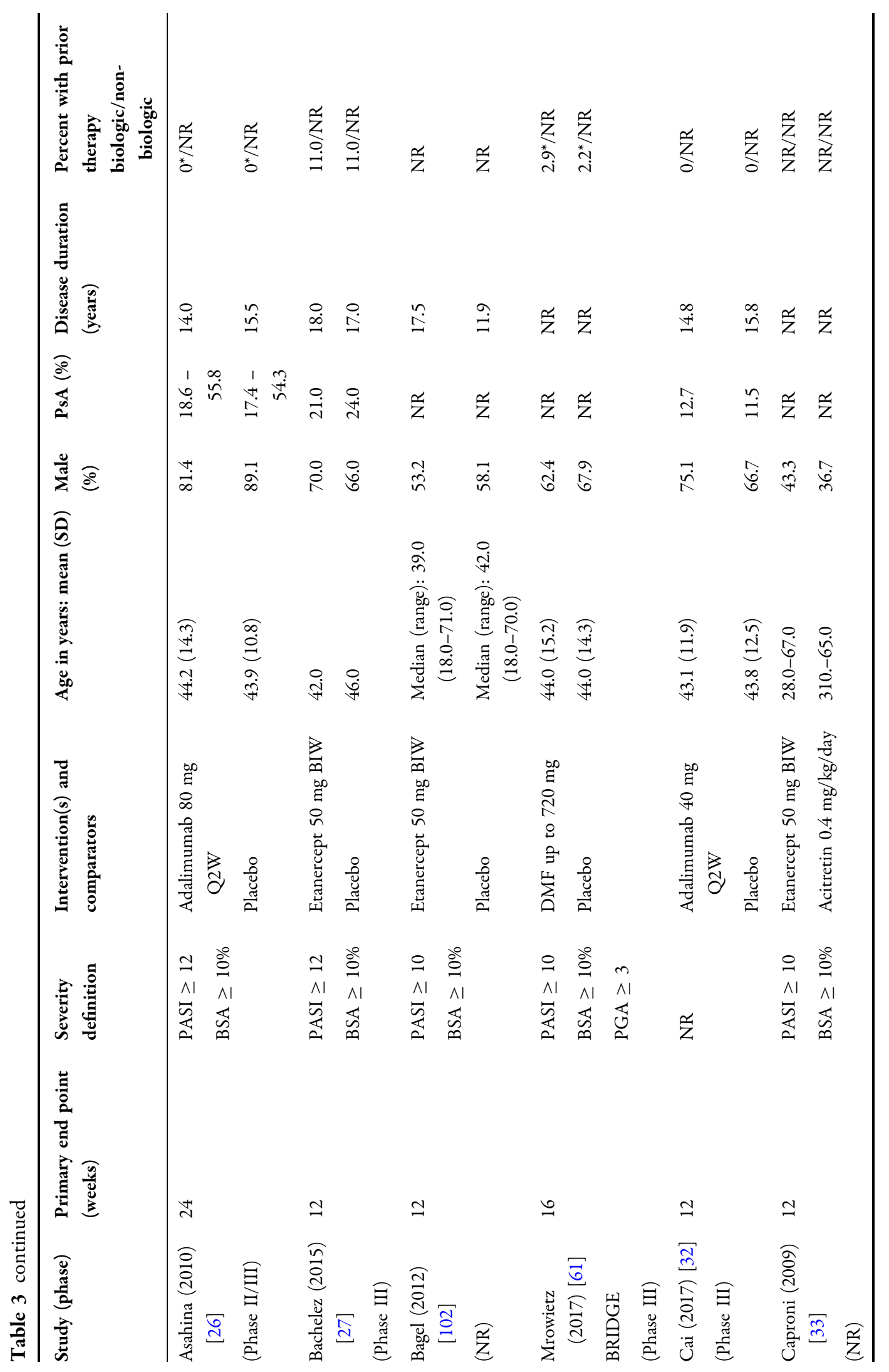




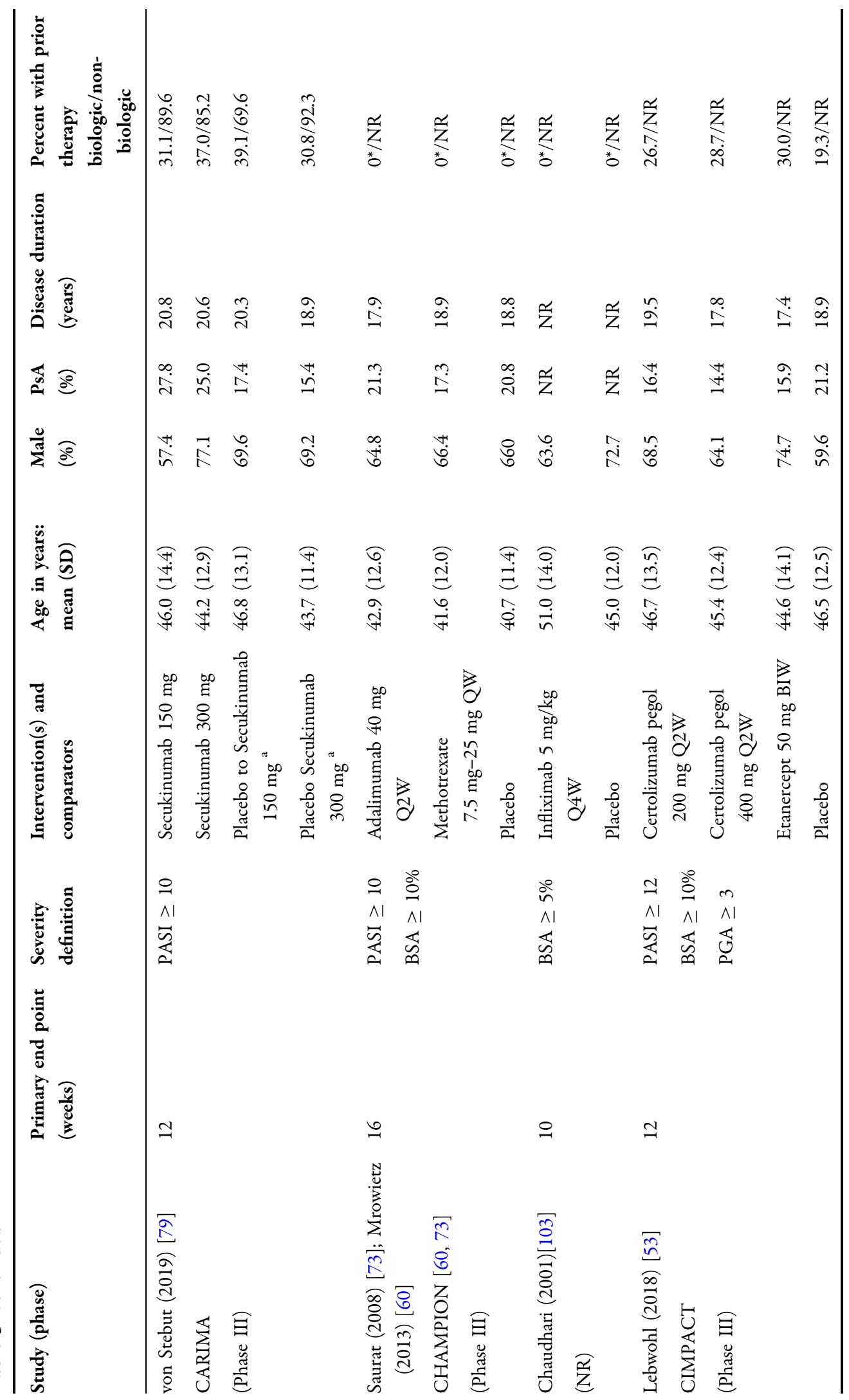




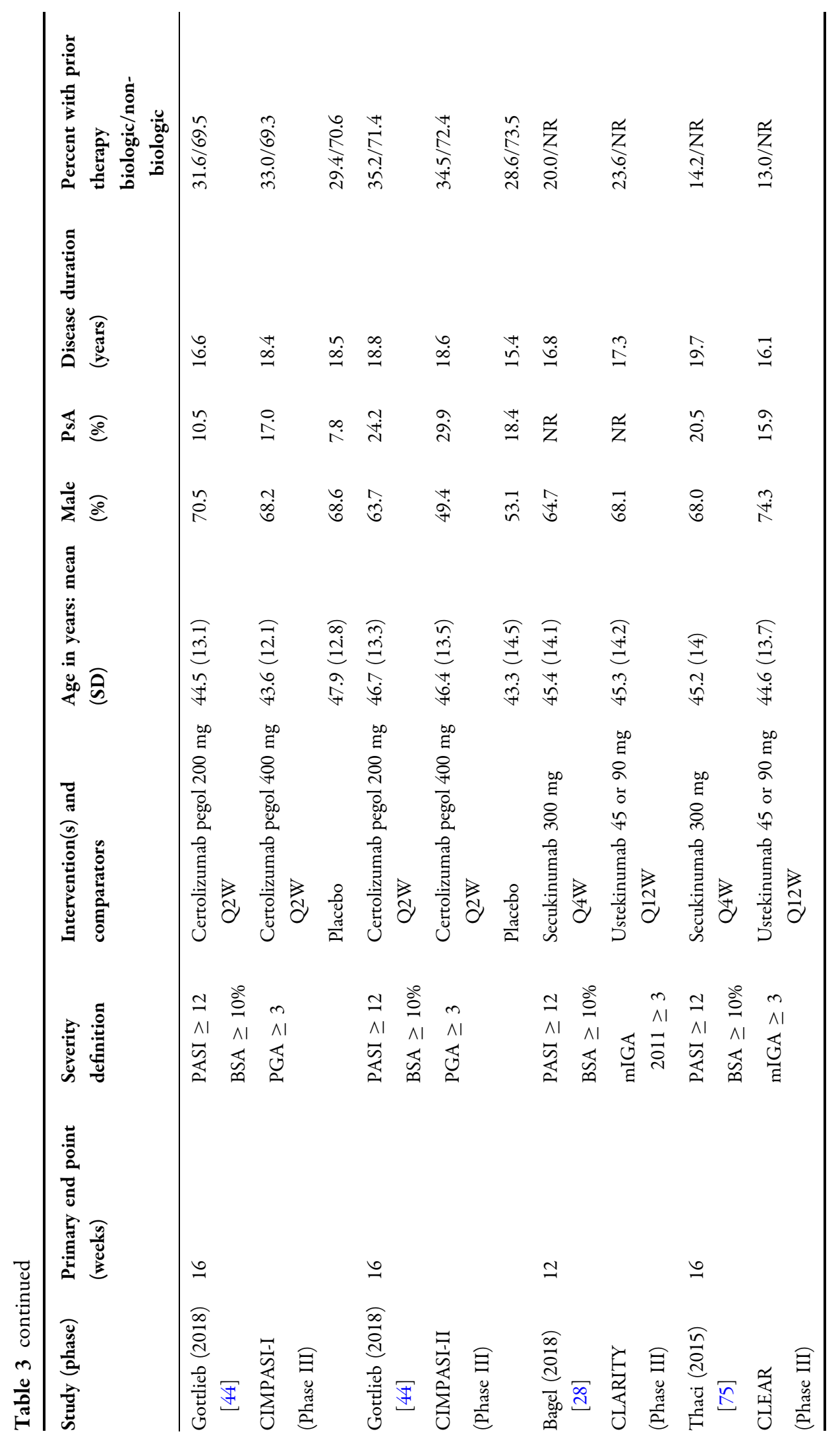




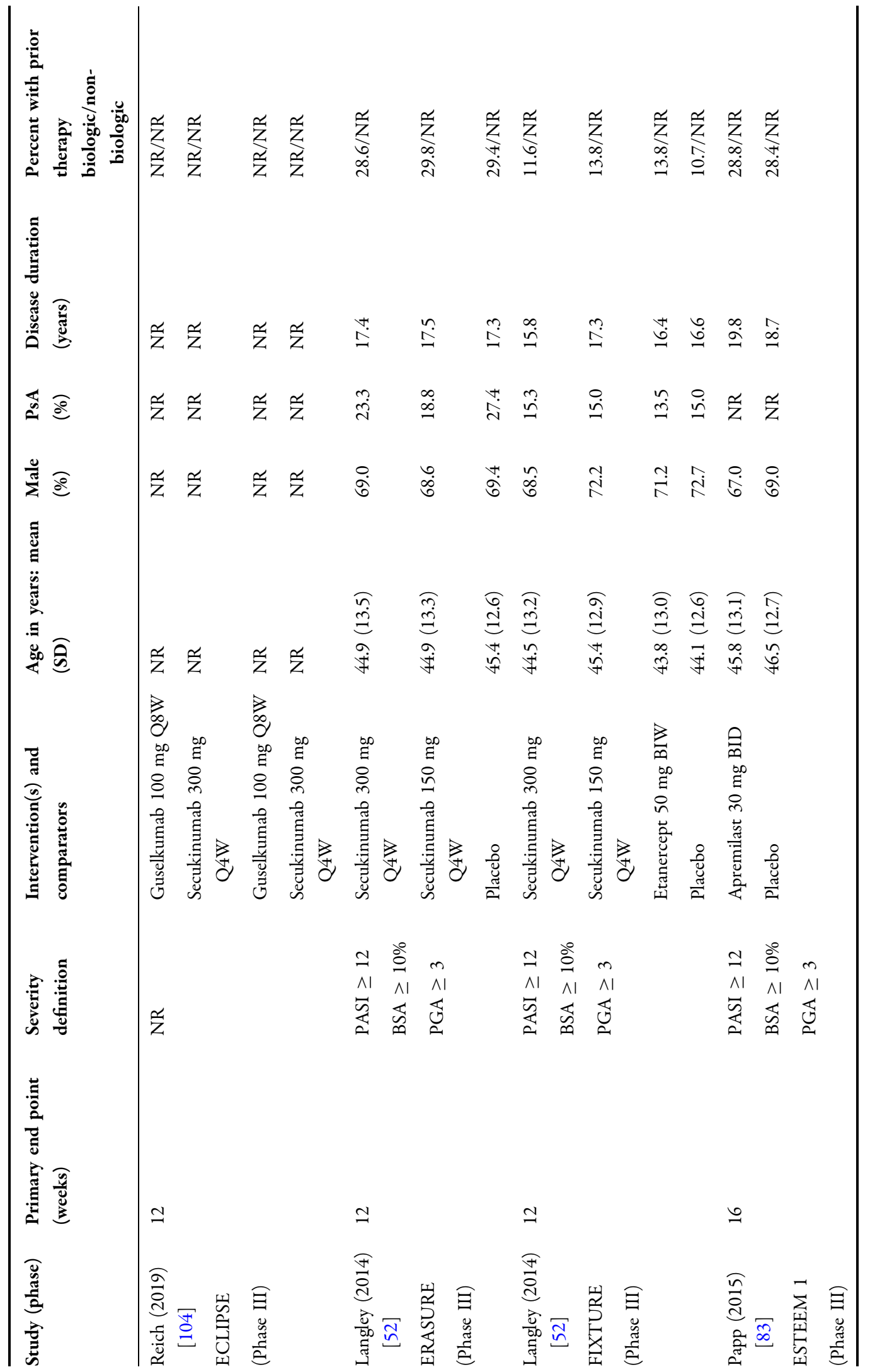




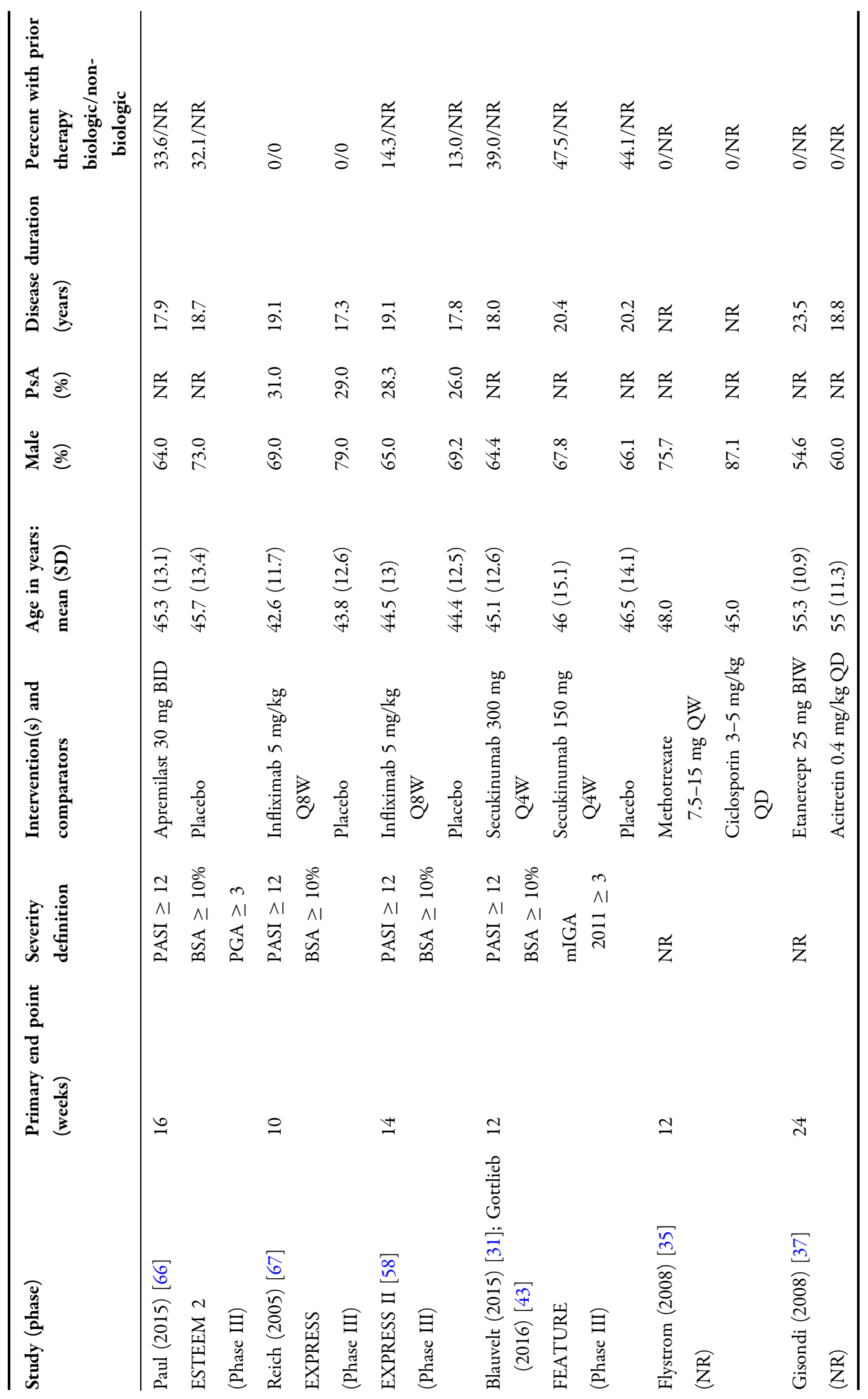




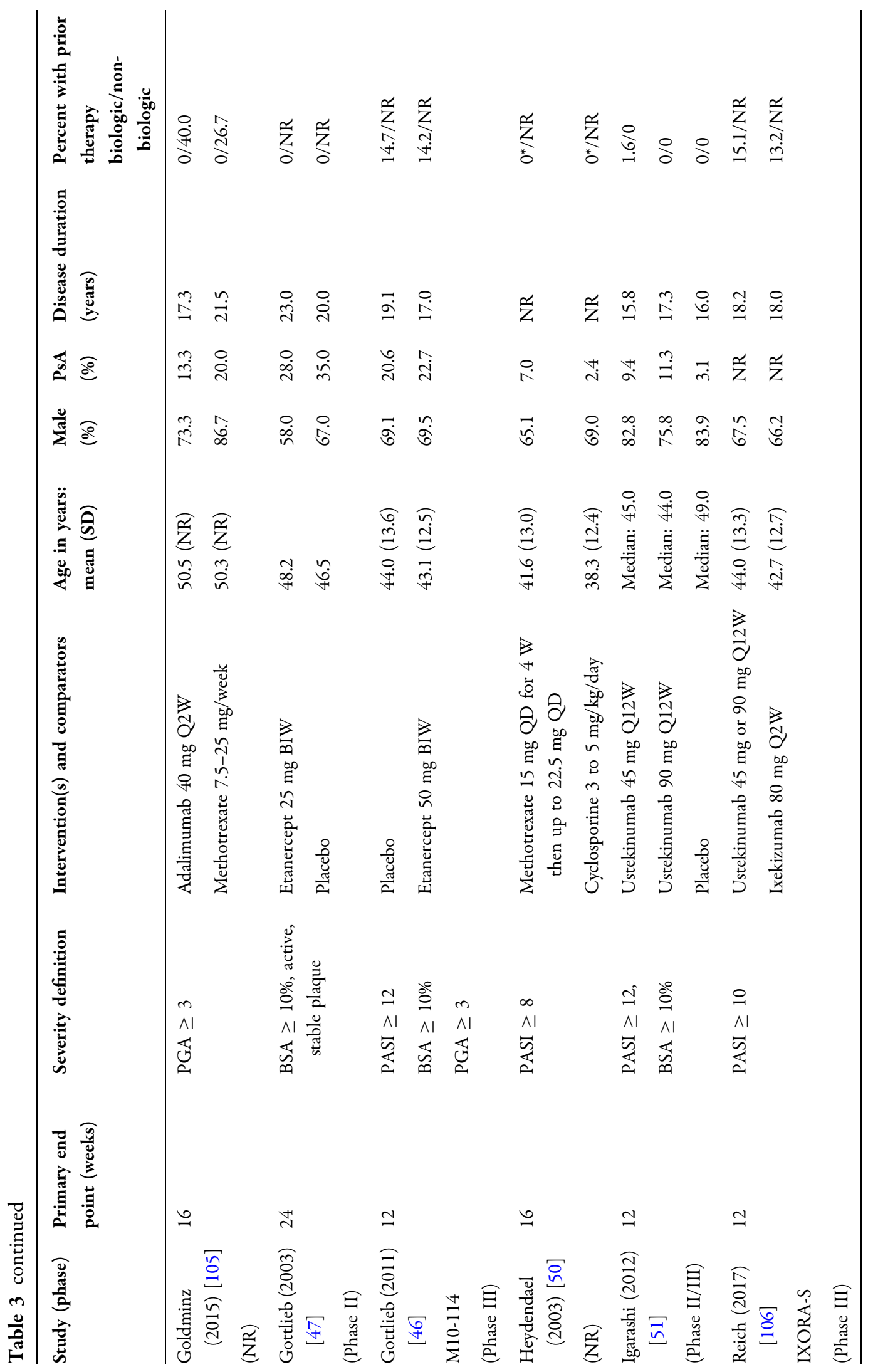




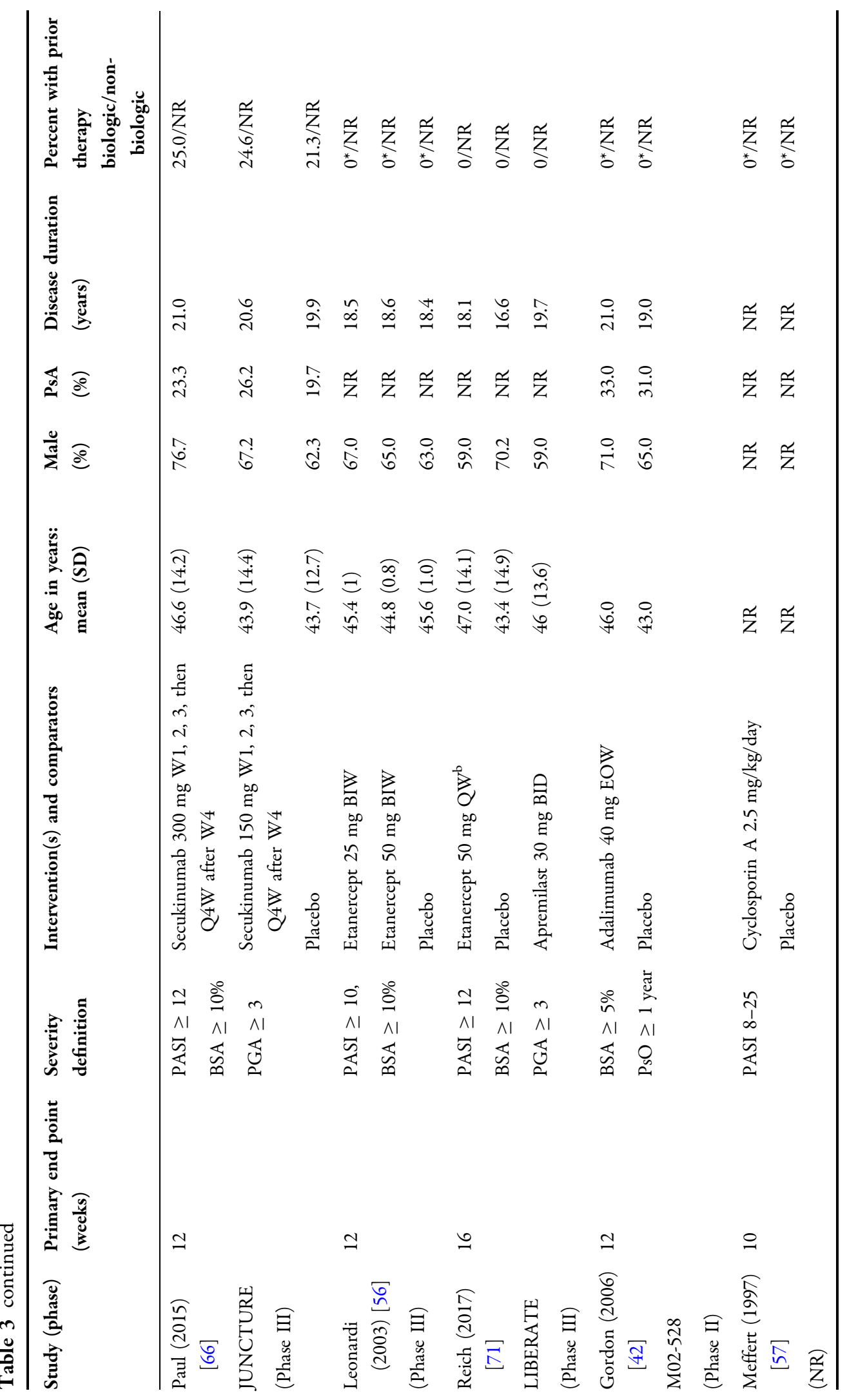




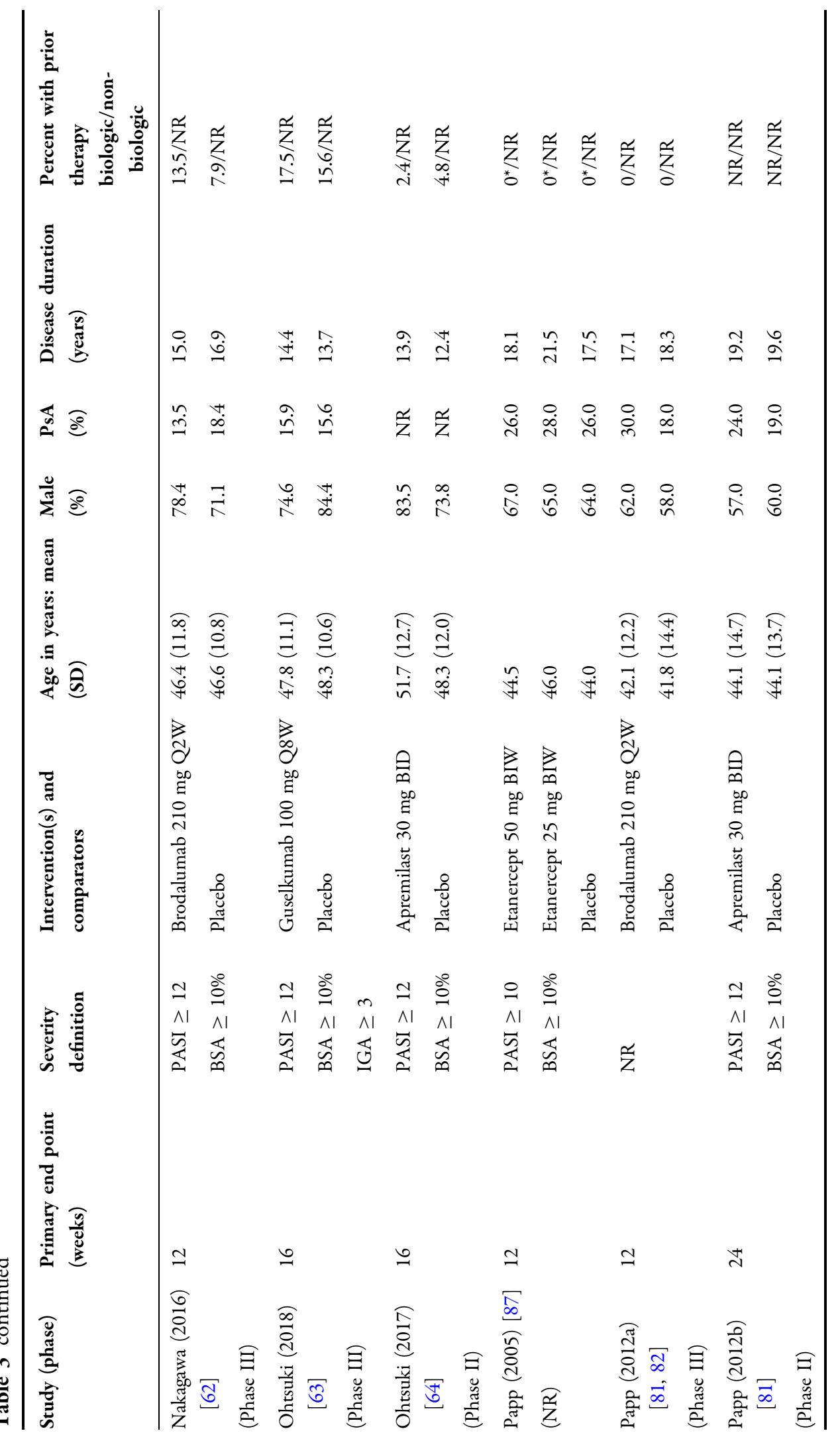




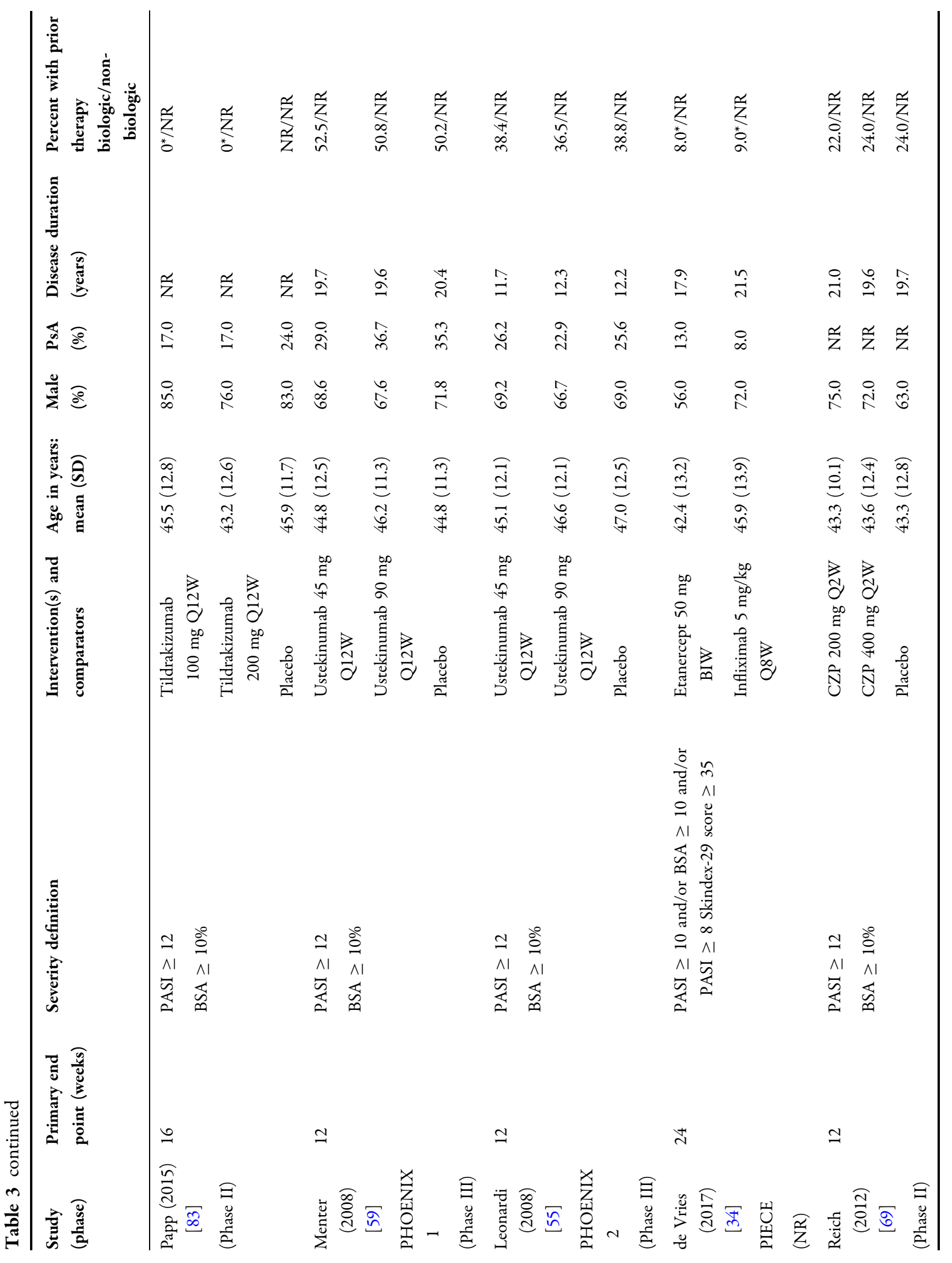




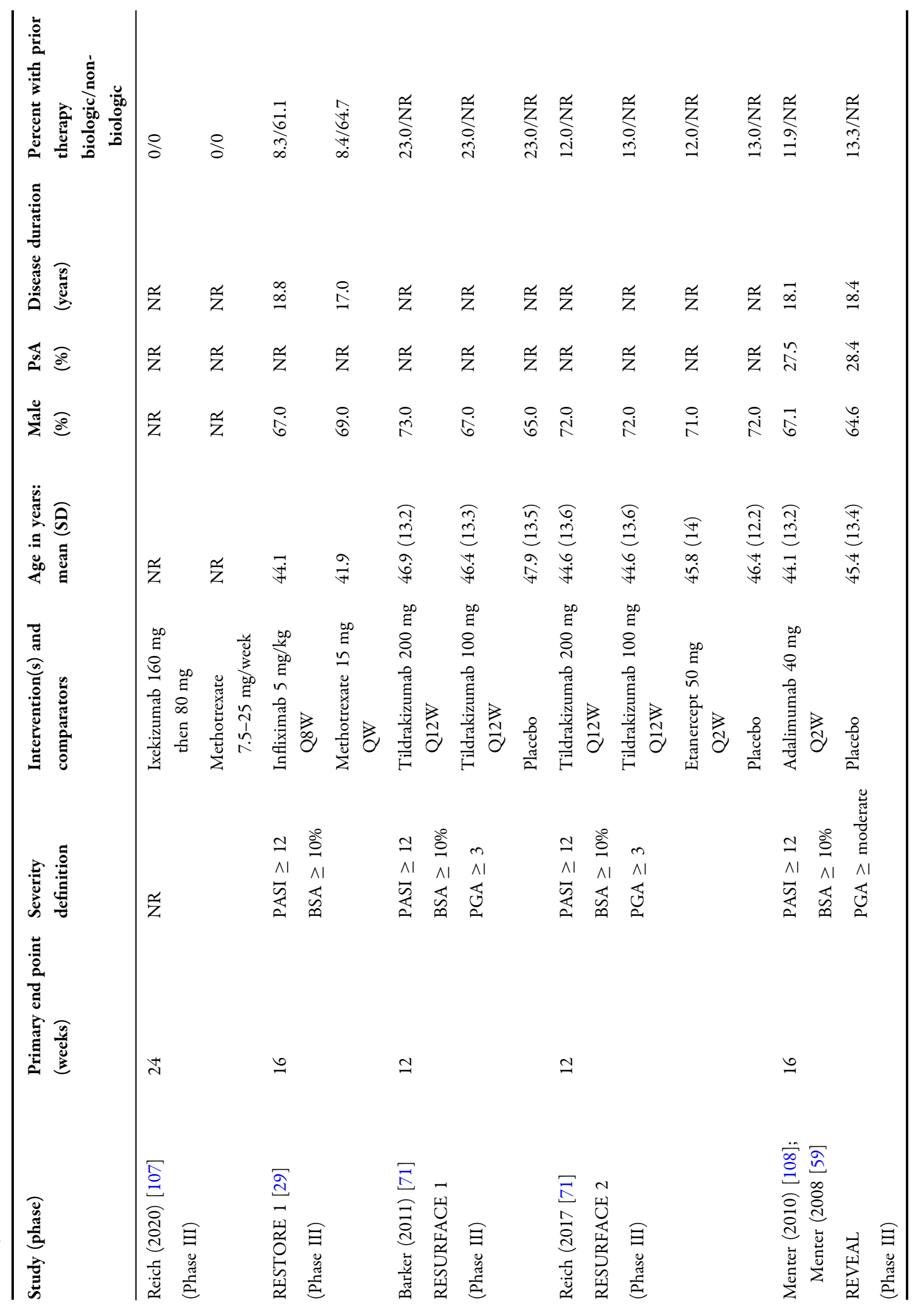




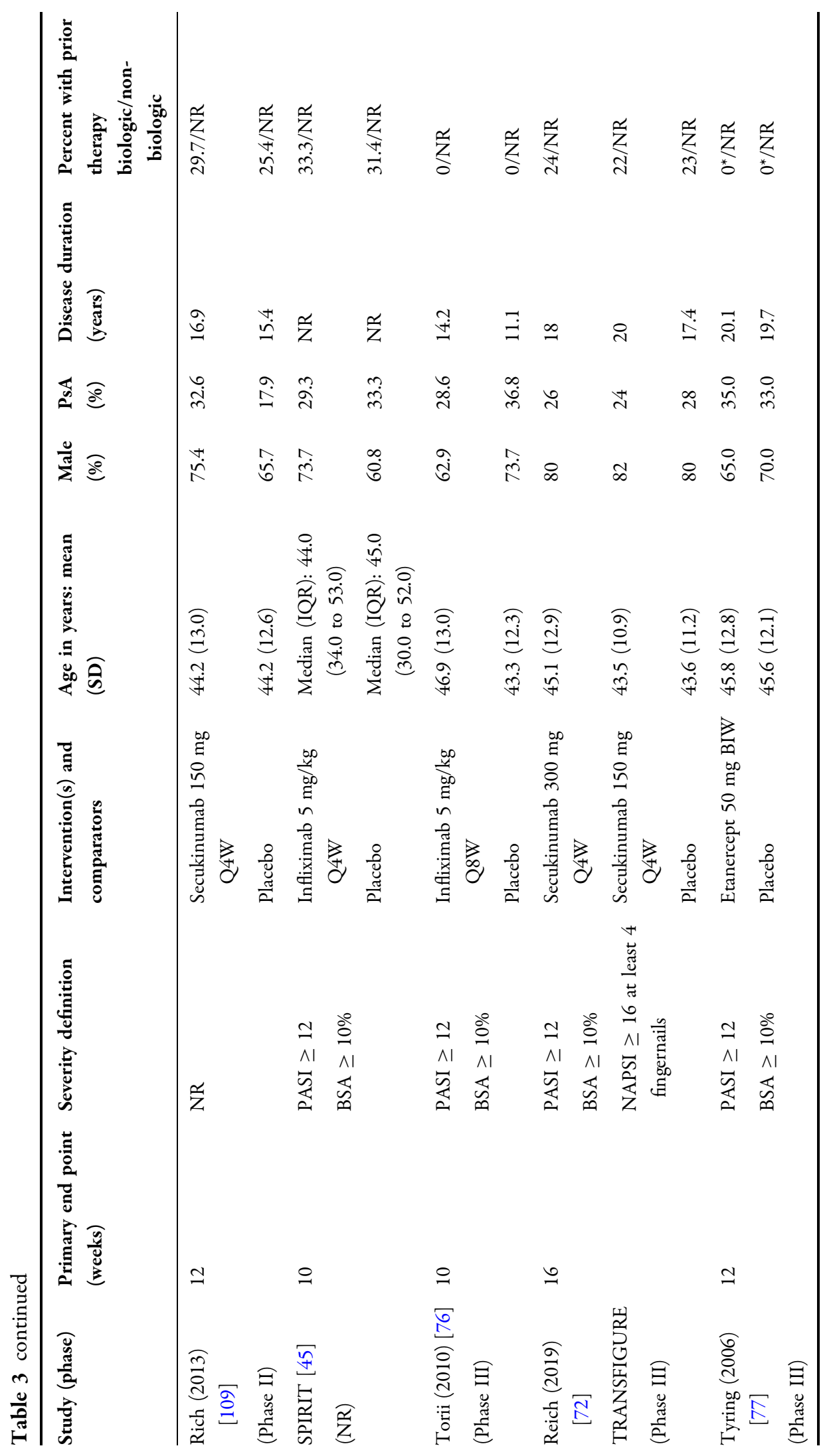




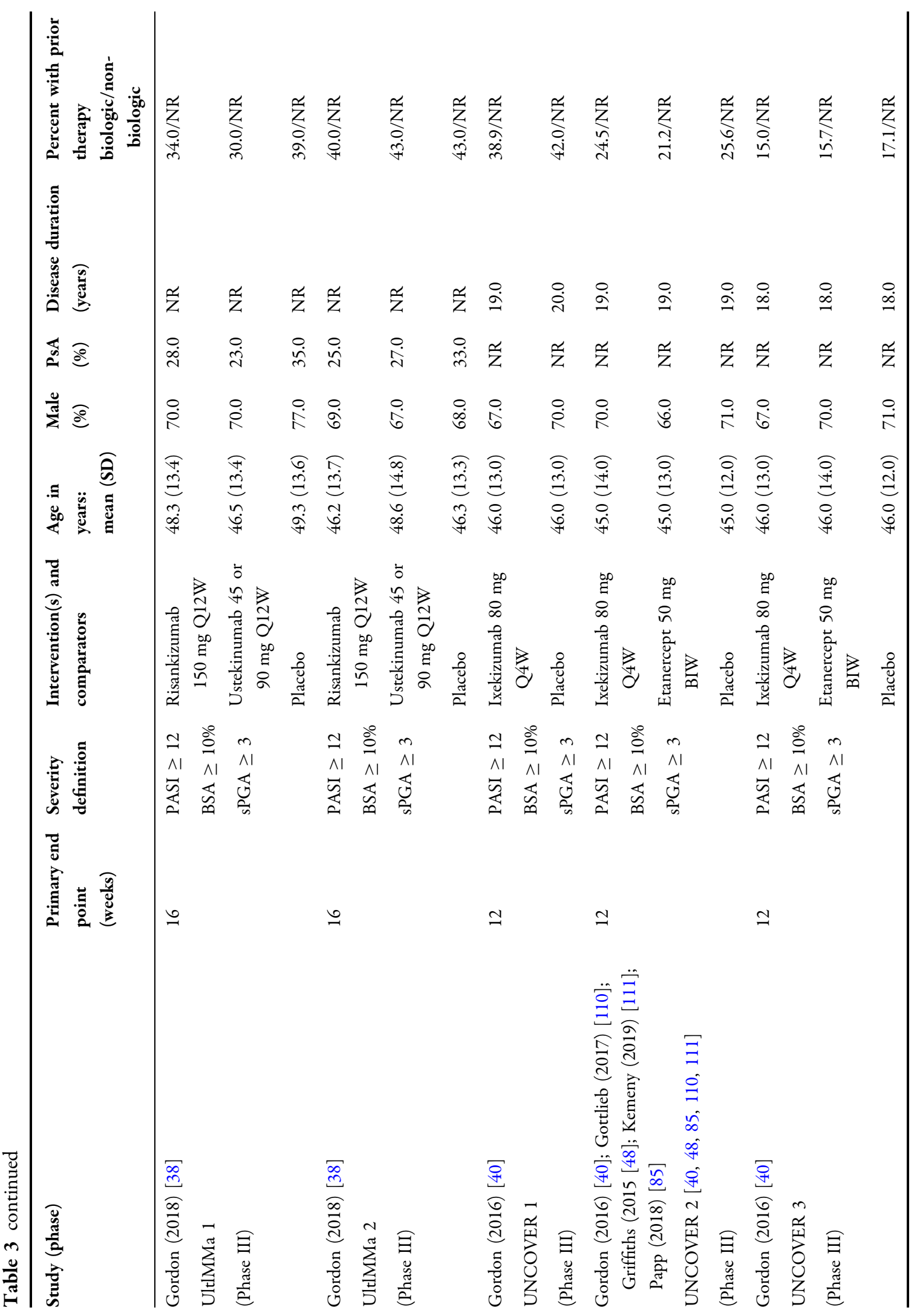




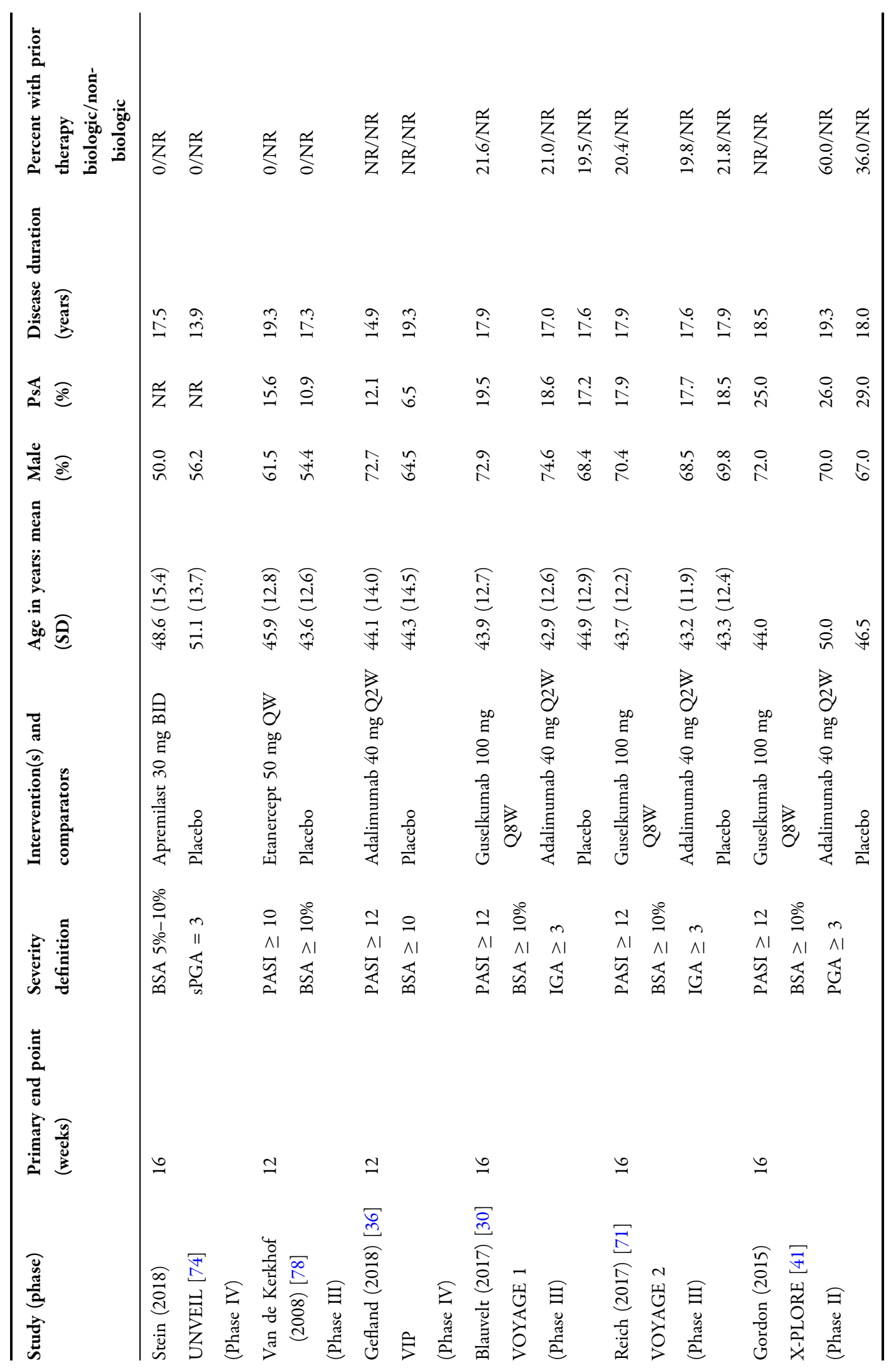




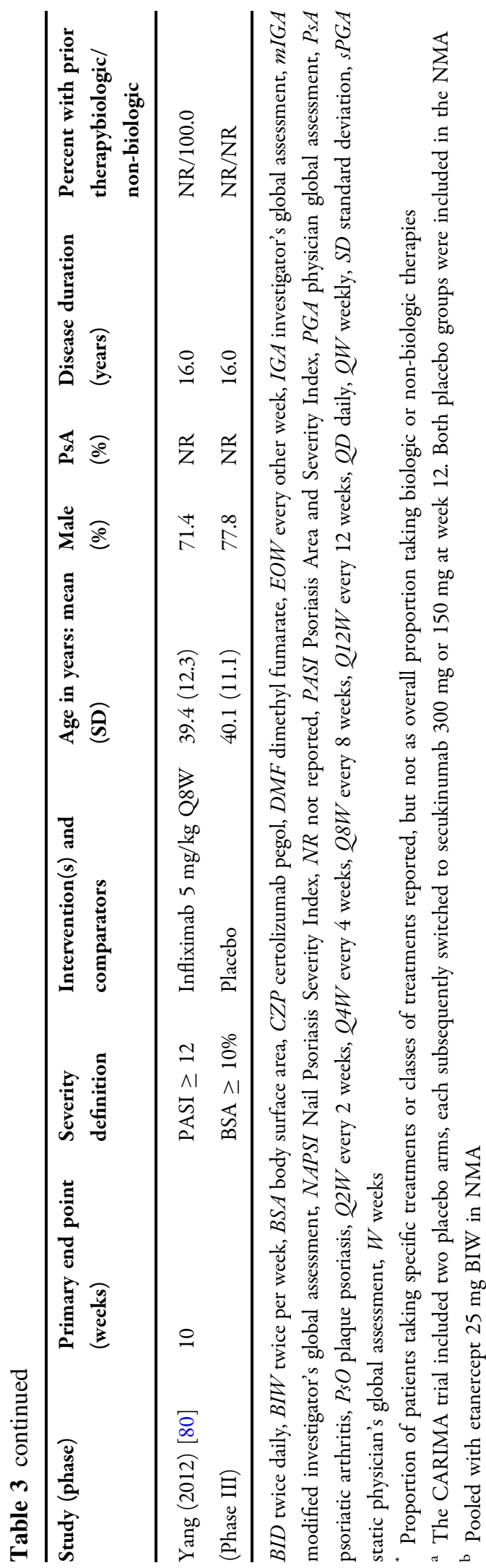

Among the TNF- $\alpha$ inhibitors, infliximab $5 \mathrm{mg} / \mathrm{kg}$ and CZP $400 \mathrm{mg}$ were better performing treatments than adalimumab and etanercept for achieving the lower levels of short-term PASI $(50,75)$, with infliximab showing a larger advantage and CZP $400 \mathrm{mg}$ being essentially equivalent to adalimumab for PASI $(90,100)$.

Treatment rankings from REZ RE baseline adjusted multinomial analysis remained nearly similar across PASI levels, as was permissible with the REZ model (Fig. 5), but even when rankings changed, estimated probabilities were very similar across TNF- $\alpha$ inhibitors other than etanercept and infliximab. Similar performances of these treatments were observed in the non-baseline risk REZ FE model (Table S7 and S8) and in the binomial sensitivity analyses (Table S9).

\section{REZ Model Versus the Standard Model}

For both FE vs. RE, and baseline-risk adjusted vs. unadjusted analyses, the REZ model had better fit than the standard model (Table 4). This was not unexpected, as the assumption that all treatments must share an exactly equivalent 'step' in between PASI cutoffs in a standard model is a strong one and would be regardless of the statistical metric. The REZ model allowed treatments to share a common step, while allowing for some variation across treatments, the amount determined by the data.

While the REZ models had better fit than the standard model under baseline risk adjustment with random-probit differences assumption, the findings were substantively similar between the two models. The REZ (Fig. 5) and standard models (Table S10) showed that the top-performing treatments were the same, though the ranking is (non-substantively) different (also see predicted probabilities from REZ [Fig. 4] and standard models [Table S11]).

Note that as drugs within treatment class could share the exact same 'steps' between PASI cutoffs (e.g., relative treatment rankings might not vary), the model could be extended to allow for variation across treatment classes instead of across treatment. The richness of the data in $\mathrm{PsO}$ trials allows the testing of a variety of approaches that allow for borrowed strength across PASI cutoffs without making the strong 
Table 4 Deviance information criterion for all multinomial-ordered probit models

\begin{tabular}{llllll}
\hline Model & $\beta_{\mathrm{BL}}(95 \% \mathrm{CrI})$ & $\widehat{\sigma}_{Z}(95 \% \mathrm{CrI})$ & $\widehat{\tau}(95 \% \mathrm{CrI})$ & $\bar{D}^{*}$ & DIC \\
\hline REZ, adjusted, FE & $-0.551(-0.667,-0.411)$ & $0.078(0.057,0.106)$ & - & 661.0 & 836.8 \\
REZ, adjusted, RE & $-0.690(-0.861,-0.533)$ & $0.078(0.056,0.106)$ & $0.103(0.066,0.148)$ & 609.8 & 832.8 \\
REZ, unadjusted, FE & - & $0.080(0.059,0.110)$ & - & 637.9 & 785.5 \\
REZ, unadjusted, RE & - & $0.080(0.059,0.110)$ & $0.103(0.045,0.160)$ & 604.6 & 813.4 \\
Standard, adjusted, FE & $-0.575(-0.689,-0.439)$ & - & - & 793.5 & 919.0 \\
Standard, adjusted, RE & $-0.715(-0.898,-0.561)$ & - & $0.104(0.068,0.149)$ & 738.6 & 914.9 \\
Standard, unadjusted, FE & - & - & - & 773.6 & 870.7 \\
Standard, unadjusted, RE & - & - & $0.113(0.053,0.170)$ & 734.9 & 897.9 \\
\hline
\end{tabular}

$C r I$ credible interval, $D I C$ deviance information criterion, $F E$ fixed effects, $R E$ random-effects, $R E Z$ model that adds a random effects component to the parameter $z$, which reflects the difficulty of moving from one PASI cutoff to the next Notations and abbreviations: $\beta_{B L}$, estimate of PBO baseline effect; $\widehat{\sigma}_{z}$, the estimate of $\sigma_{z}$, the standard deviation of each $z_{i j}$ $(j=1,2, \ldots$, maximum number of PASI cutoffs minus one); $\widehat{\tau}$, the estimate of $\tau$, the common between-study standard deviation on the probit differences; $\bar{D}$, the mean deviance at residual; DIC, the deviance information criteria at residual

* The total number of data points was 484 from 172 treatment arms from 72 studies. A treatment arm in a study with data on PASI50 and PASI75 contributes two data points as two independent PASI response categories of 50 to $<75 \%$ and $75-100 \%$ responses are modeled (where the response category of $0-50 \%$ is computed from arm size and PASI 50 )

assumption that all treatments will have precisely the same ranking, from PASI50 through PASI100.

\section{Patients Nä̈ve to Previous Biologic Treatment (Subgroup Analysis)}

Thirty-five RCTs reported subgroup data for populations that were $100 \%$ naïve to previous biologic treatment, and six additional studies had data for $\geq 90 \%$ but $<100 \%$ naïve (Figs. S1 and S2). In the $\geq 90 \%$ naïve biologic-naive population, risankizumab $150 \mathrm{mg}$ outperformed all available treatments across all PASI levels, followed by brodalumab $210 \mathrm{mg}$, guselkumab $100 \mathrm{mg}$, and ixekizumab $80 \mathrm{mg}$. Among the TNF- $\alpha$ inhibitors, CZP $400 \mathrm{mg}$ performed better than infliximab, adalimumab, and etanercept across all PASI levels (Fig. S3).

When the cutoff for the percentage of patients that are treatment naïve was adjusted to a more stringent $100 \%$, dimethyl fumarate fell out of the network. Similar findings were obtained in the $100 \%$ biologic-naive population with the following exception: infliximab $5 \mathrm{mg} /$ $\mathrm{kg}$ performed better than CZP $400 \mathrm{mg}$ in achieving PASI 75 only. The conclusions in this subgroup analysis reflected those of the basecase analysis, with the IL inhibitors showing the best efficacy across PASI levels (Fig. S4).

\section{DISCUSSION}

This review considered only licensed dosages and restricted PASI outcomes to 10-16 weeks-a clinically relevant time point to assess whether $\mathrm{PsO}$ treatments produce a positive effect on patients. It considered peer-reviewed and gray literature evidence to avoid publication bias, and screening and data extraction were conducted by two independent reviewers.

The NMA analysis enabled us to produce indirect treatment comparative effect estimates for biologics that were compared in RCTs, while adjusting for the effect of differences in baseline placebo rates. The biologics were associated with better probability of achieving all PASI response levels compared with non-biologics and placebo. All biologics except etanercept had $>80 \%$ probability of achieving PASI50. Except for tildrakizumab (200 $\mathrm{mg}$ and $100 \mathrm{mg}$ ), the IL inhibitors were the best-performing 


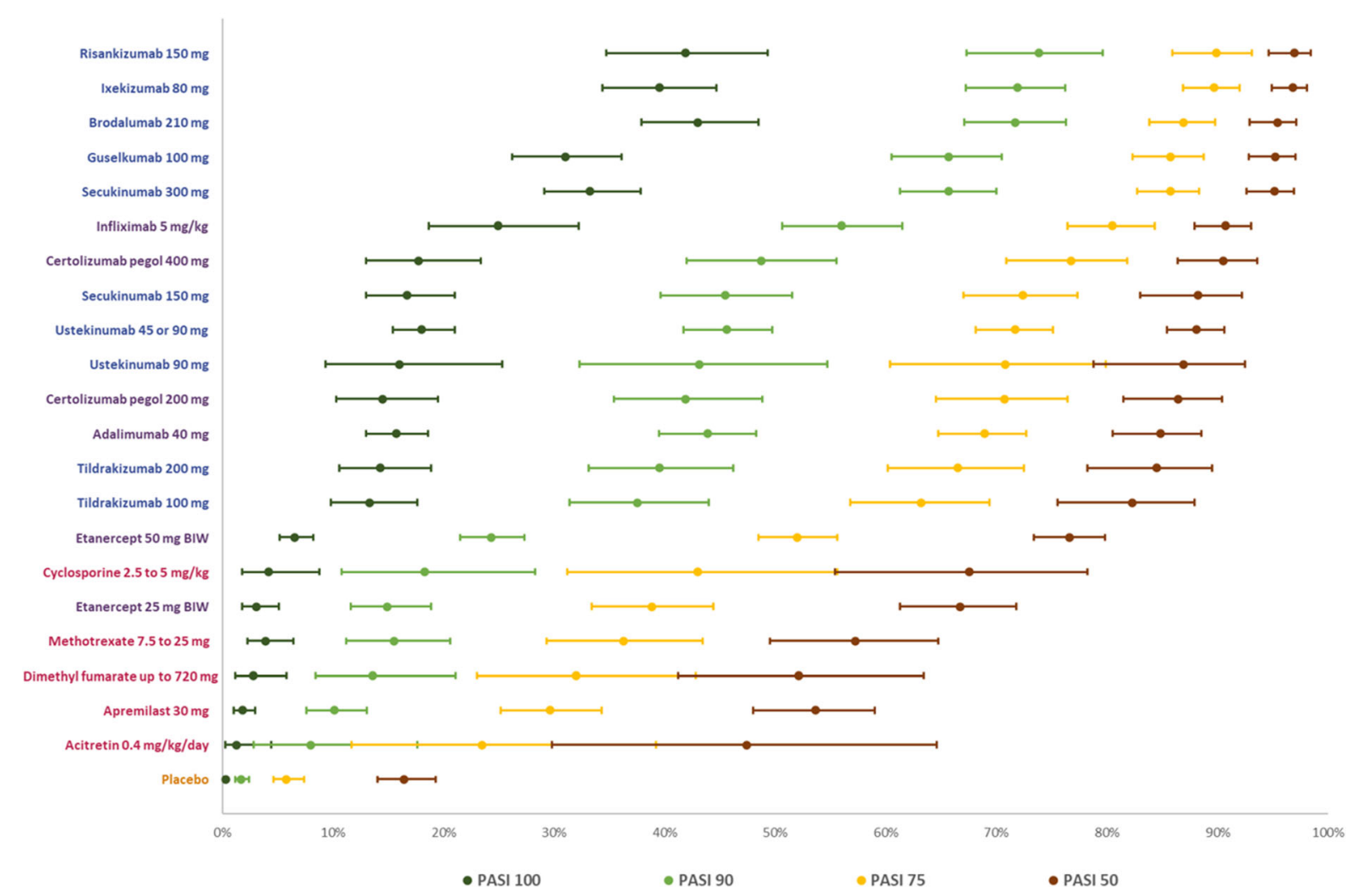

Fig. 4 Predicted probabilities of achieving PASI responses at 10-16 weeks in baseline adjusted REZ random effects multinomial model. Treatments are sorted by the highest to lowest estimates of probabilities of reaching PASI75

treatments for achieving all levels of short-term PASI (50, 75, 90, and 100). CZP $400 \mathrm{mg}$ and infliximab $5 \mathrm{mg} / \mathrm{kg}$ performed the best among the TNF- $\alpha$ inhibitors. The validity of our basecase analysis was reinforced by similar results from two sensitivity analyses (a baseline-unadjusted model and an analysis restricted to biologic-naïve populations).

These results should be interpreted in light of the following limitations. Our SLR search cutoff point (March 2019) may have missed trials of newer treatments approved after this date. The analysis was limited to PASI outcomes to evaluate clinical efficacy and did not consider other efficacy outcomes which may have provided additional value to the performance of treatments. Our analysis was restricted to the efficacy of treatments in a 10- to 16-week period, which may not reflect patients' long-term experiences. Additionally, all NMAs assume that populations and study designs/methods across trials are homogeneous enough for the valid estimation of indirect treatment effects. While studies had similar populations and all used the PASI, we cannot rule out that some differences in patient characteristics might have influenced results. Generally, a signal such as heterogeneity in study results indicates a problem, although the global estimate of heterogeneity was quite low. We also found similar results when restricting analyses to biologic-naïve patients, suggesting that variation in previous biologics was unlikely a source of heterogeneity.

Previous NMAs [17, 69, 90-98] investigated the comparative effects estimates between different biologic and non-biologic treatments for patients with moderate-to-severe PsO; however, the scope of many of these publications differed from ours (e.g., some NMAs restricted the analysis to comparisons of specific treatments or treatment class). Our analysis results were generally consistent with previous findings in 


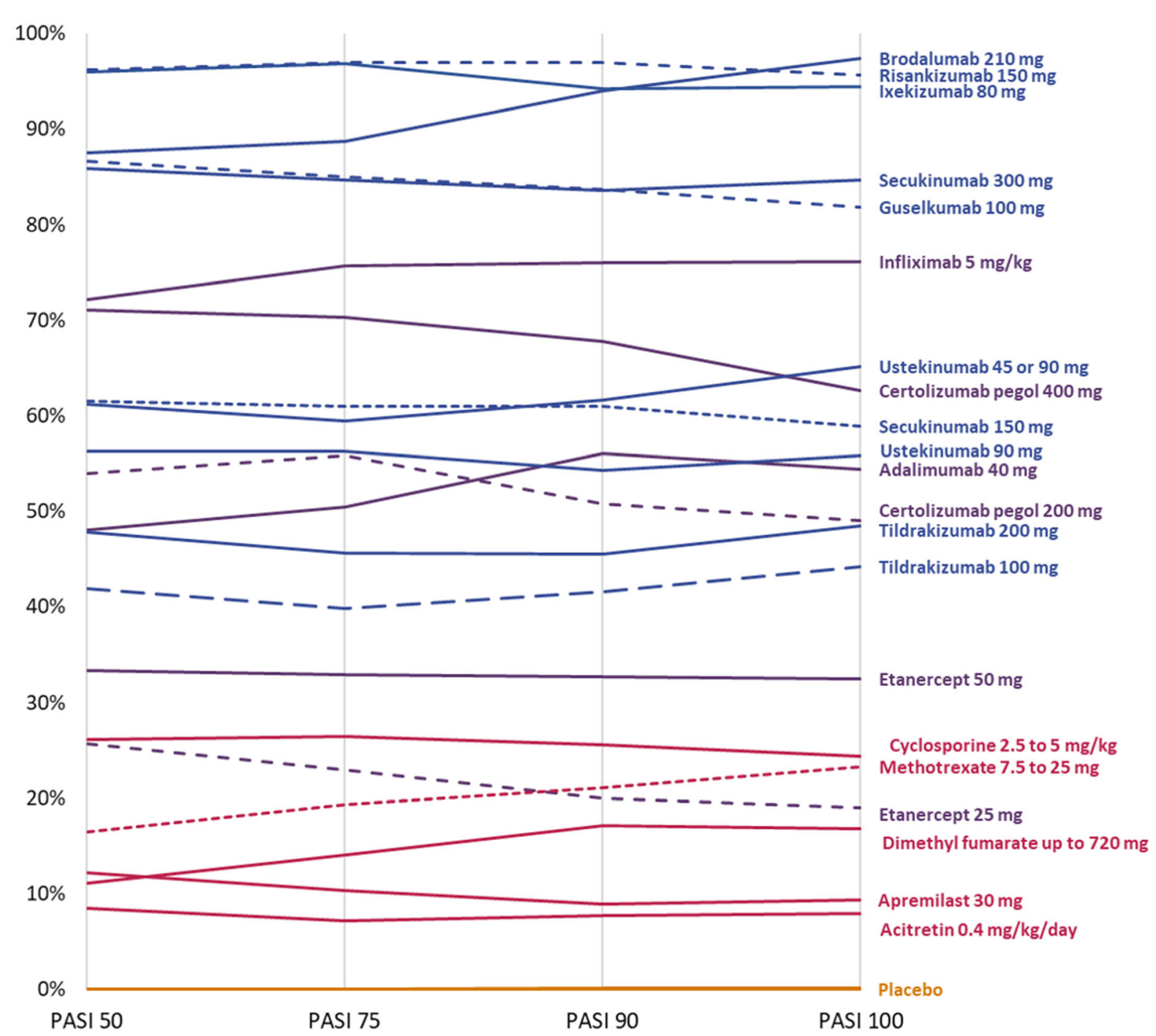

SUCRA, surface under cumulative ranking curve.

* SUCRAs were calculated ranking posterior samples of response probabilities of achieving each PASI level.

Different line patterns are for visual distinction and do not represent different groups. The colors distinguish drug classes: Yellow $=$ placebo; blue $=$ interleukin inhibitors; purple $=$ TNF- $\alpha$ inhibitors; red $=$ non-biologic treatments

Fig. 5 SUCRA* plot of treatments achieving each PASI threshold in baseline adjusted REZ random-effects multinomial model

Armstrong (2020) [22] and Sawyer (2019) [95], which used a multinomial approach with adjustment for baseline risk. There are distinct methodologic differences with the planning of our evidence generation and analysis, making these NMA results more robust in providing reliable effect and comparative effect estimates among the biologics. For example, we restricted our protocol to approved treatments with licensed dosages with a reasonably adequate sample size and with a restricted follow-up period (10-16 weeks) to allow interpretation of results in a healthcare decision-making setting. The recent Cochrane review published on the same topic adopted a different protocol with a broader scope that allowed inclusion of trials 
testing non-approved treatments, of any sample size, reporting on outcomes in a wider range of follow-up (8-24 weeks) periods and employing different analytic approaches (multivariate modeling), limiting direct comparability of treatments effect estimates between this study and the Cochrane review [96].

Wright et al. recently published an SLR of 25 NMAs conducted in PsO [98]. The authors reported that the choice of multinomial vs. binomial models had minimal impact on the results. Six of the NMAs in the SLR adjusted for placebo rate, and, in all cases, those models found a better fit for the adjusted over the unadjusted model, supporting this approach. Across the short-term NMAs of PASI 75 and 90, ixekizumab, brodalumab, and risankizumab tended to rank in the top three when evaluated, with ixekizumab ranking first in most NMAs, and second in the remainder, including our study. Secukinumab, infliximab, adalimumab, and guselkumab tended to rank next, with etanercept, certolizumab pegol, ustekinumab, and tildrakizumab tending to rank lowest. Our NMA yielded comparable results, with risankizumab, ixekizumab, and brodalumab as the topranking treatments.

\section{CONCLUSIONS}

Our study confirmed that IL inhibitors are likely the best short-term treatment choices for improving all PASI levels. The findings from our enhanced NMA analyses, which considered additional methodologic approaches using the richness of the trial data, provide clinicians and researchers with reliable comparative estimates of biologics in moderate-to-severe $\mathrm{PsO}$ and allow further application of similar methodologies in other disease areas with similar analytical challenges, such as PsA.

\section{ACKNOWLEDGEMENTS}

Funding. This study and the Journal's Rapid Service Fee were funded by UCB Pharma Ltd., Slough, UK.
Medical Writing and/or Editorial Assistance and Additional Support. Authors thank Vanessa Taieb from UCB for providing support for visualization. Authors also thank Marissa Betts, Paulina Kazmierska, and Mahmoud Slim from Evidera for manuscript revisions. Editorial assistance in the preparation of this article was provided by Dawn Ri'chard from Evidera.

Authorship. All named authors meet the International Committee of Medical Journal Editors (ICMJE) criteria for authorship for this article, take responsibility for the integrity of the work as a whole, and have given their approval for this version to be published.

Author Contributions. Substantial contributions to study conception and design: KF, GS; substantial contributions to analysis and interpretation of the data: KF, GS, DMP, BN, SEM, SK, KR; drafting the article or revising it critically for important intellectual content: KF, GS, DMP, BN, SEM, SK, KR; final approval of the version of the article to be published: KF, GS, DMP, BN, SEM, SK, KR.

Disclosures. KF, BN: employed by Evidera, Inc., by PPD; GS and SM were employees of Evidera at the time the research was conducted.DMP: received consultancy fees from UCB; SK: employed by UCB Pharma; KR: Served as advisor and/or paid speaker for and/or participated in clinical trials sponsored by AbbVie, Affibody, Almirall, Amgen, Avillion, Biogen, Boehringer Ingelheim, Bristol Myers Squibb, Celgene, Centocor, Covagen, Dermira, Eli Lilly, Forward Pharma, Fresenius Medical Care, Galapagos, Galderma, GSK, Janssen, Kyowa Kirin, LEO Pharma, Medac, MSD, Miltenyi Biotec, Novartis, Ocean Pharma, Pfizer, Regeneron, Samsung Bioepis, Sanofi, Sun Pharma, Takeda, UCB Pharma, Valeant/Bausch Health, and Xenoport.

Compliance with Ethics Guidelines. This article is based on previously conducted studies and does not contain any new studies with human participants or animals performed by any of the authors. 
Data Availability. The datasets generated during and/or analyzed during the current study are available from the corresponding author on reasonable request.

Open Access. This article is licensed under a Creative Commons Attribution-NonCommercial 4.0 International License, which permits any non-commercial use, sharing, adaptation, distribution and reproduction in any medium or format, as long as you give appropriate credit to the original author(s) and the source, provide a link to the Creative Commons licence, and indicate if changes were made. The images or other third party material in this article are included in the article's Creative Commons licence, unless indicated otherwise in a credit line to the material. If material is not included in the article's Creative Commons licence and your intended use is not permitted by statutory regulation or exceeds the permitted use, you will need to obtain permission directly from the copyright holder. To view a copy of this licence, visit http://creativecommons.org/licenses/by$\mathrm{nc} / 4.0 /$.

\section{REFERENCES}

1. Mantovani L, Medaglia M, Piacentini P, et al. Burden of moderate-to-severe plaque psoriasis and new therapeutic approaches (secukinumab): an Italian Perspective. Dermatol Ther (Heidelb). 2016;6(2): 151-67.

2. Gottlieb A, Korman NJ, Gordon KB, et al. Guidelines of care for the management of psoriasis and psoriatic arthritis: section 2. Psoriatic arthritis: overview and guidelines of care for treatment with an emphasis on the biologics. J Am Acad Dermatol. 2008;58(5):851-64.

3. Menter A, Gottlieb A, Feldman SR, et al. Guidelines of care for the management of psoriasis and psoriatic arthritis: section 1. Overview of psoriasis and guidelines of care for the treatment of psoriasis with biologics. J Am Acad Dermatol. 2008;58(5):826-50.

4. Gelfand JM, Troxel AB, Lewis JD, et al. The risk of mortality in patients with psoriasis: results from a population-based study. Arch Dermatol. 2007;143(12):1493-9.
5. Smith $\mathrm{CH}$, Anstey AV, Barker JN, et al. British Association of Dermatologists' guidelines for biologic interventions for psoriasis 2009. Br J Dermatol. 2009;161(5):987-1019.

6. Johansson E, Nunez M, Svedbom A, Dilla T, Hartz S. Cost effectiveness of ixekizumab versus secukinumab in the treatment of moderate-to-severe plaque psoriasis in Spain. Clinicoecon Outcomes Res. 2018;10:747-59.

7. Mariette X, Förger F, Abraham B, et al. Lack of placental transfer of certolizumab pegol during pregnancy: results from CRIB, a prospective, postmarketing, pharmacokinetic study. Ann Rheum Dis. 2018;77(2):228-33.

8. Baker T, Kevorkian L, Nesbitt A. FRI0162 Investigation into the binding affinity of certolizumab pegol to FcRn and functional consequences for FcRn-mediated transcytosis: comparison to infliximab, adalimumab and etanercept. Ann Rheum Dis. 2013;72(Suppl 3):A426.

9. Weir N, Athwal D, Brown D, et al. A new generation of high-affinity humanized PEGylated Fab' fragment anti-tumor necrosis factor-alpha monoclonal antibodies. Therapy. 2006;3(4):535-45.

10. Caldwell DM, Ades AE, Higgins JP. Simultaneous comparison of multiple treatments: combining direct and indirect evidence. BMJ. 2005;331(7521): 897-900.

11. Mattei PL, Corey KC, Kimball AB. Psoriasis Area Severity Index (PASI) and the Dermatology Life Quality Index (DLQI): the correlation between disease severity and psychological burden in patients treated with biological therapies. J Eur Acad Dermatol Venereol. 2014;28(3):333-7.

12. The Cochrane Collaboration. Cochrane Handbook for Systematic Reviews of Interventions (June 2017: Handbook Editors' Update). March 2011. http:// handbook.cochrane.org/. Accessed 3 Feb 2020.

13. Liberati A, Altman DG, Tetzlaff J, et al. The PRISMA statement for reporting systematic reviews and meta-analyses of studies that evaluate healthcare interventions: explanation and elaboration. BMJ. 2009;339:b2700.

14. Jansen JP, Fleurence R, Devine B, et al. Interpreting indirect treatment comparisons and network metaanalysis for health-care decision making: report of the ISPOR Task Force on Indirect Treatment Comparisons Good Research Practices: part 1. Value Health. 2011;14(4):417-28.

15. Higgins JPT. The Cochrane Collaboration's tool for assessing risk of bias in randomised trials. BMJ. 2011;343:d59228. 
16. Salanti G. Indirect and mixed-treatment comparison, network, or multiple-treatments meta-analysis: many names, many benefits, many concerns for the next generation evidence synthesis tool. Res Synth Methods. 2012;3(2):80-97.

17. Cameron C, Hutton B, Druchok C, et al. Importance of assessing and adjusting for cross-study heterogeneity in network meta-analysis: a case study of psoriasis. J Comp Eff Res. 2018;7(11):1037-51.

18. Dias S, Welton N, Sutton A, Ades AE. NICE DSU Technical Support Document 2: A Generalised Linear Modelling Framework for Pairwise and Network Meta-Analysis of Randomised Controlled Trials. 2011. http://nicedsu.org.uk/wp-content/uploads/ 2016/03/A-general-linear-modelling-framework-forpair-wise-and-network-meta-analysis-ofrandomised-controlled-trials..pdf. Accessed 2 Nov 2017.

19. Dias S, Sutton A, Welton N, Ades AE. NICE DSU Technical Support Document 3: Heterogeneity: Subgroups, Meta-Regression, Bias and Bias-Adjustment. 2011. http://nicedsu.org.uk/wp-content/ uploads/2016/03/TSD3-Heterogeneity.final-report. 08.05.12.pdf. Accessed 2 Nov 2017.

20. Dias S, Sutton A, Welton N, Ades AE. NICE DSU Technical Support Document 5: Evidence Synthesis in the Baseline Natural History Model. 2012. http:// nicedsu.org.uk/wp-content/uploads/2016/03/TSD5Baseline.final-report.08.05.12.pdf. Accessed $2 \mathrm{Nov}$ 2017.

21. Wade R, Grosso A, South E, et al. Brodalumab for the treatment of moderate-to-severe plaque psoriasis: an evidence review group evaluation of a NICE Single Technology Appraisal. Pharmacoeconomics. 2019;37(2):131-9.

22. Armstrong AW, Puig L, Joshi A, et al. Comparison of biologics and oral treatments for plaque psoriasis: a meta-analysis. JAMA Dermatol. 2020;156(3): 258-69.

23. Gelman A. Chapter 8: inference and monitoring convergence. In: Gilks WR, Richardson S, Spiegelhalter DJ, editors. Markov Chain Monte Carlo in practice. US: Chapman \& Hall/CRC Interdisciplinary Statistics; 1996. p. 131-43.

24. Brooks SP, Gelman A. General methods for monitoring convergence of iterative simulations. J Comput Graph Stat. 1998;7(4):434-55.

25. Salanti G, Ades AE, Ioannidis JP. Graphical methods and numerical summaries for presenting results from multiple-treatment meta-analysis: an overview and tutorial. J Clin Epidemiol. 2011;64(2): 163-71.
26. Asahina A, Nakagawa H, Etoh T, Ohtsuki M, Adalimumab MSG. Adalimumab in Japanese patients with moderate to severe chronic plaque psoriasis: efficacy and safety results from a Phase II/III randomized controlled study. J Dermatol. 2010;37(4): 299-310.

27. Bachelez H, van de Kerkhof PC, Strohal R, et al. Tofacitinib versus etanercept or placebo in moderate-to-severe chronic plaque psoriasis: a phase 3 randomised non-inferiority trial. Lancet. 2015;386(9993):552-61.

28. Bagel J, Nia J, Hashim PW, et al. Secukinumab is superior to ustekinumab in clearing skin in patients with moderate to severe plaque psoriasis (16-Week CLARITY Results). Dermatol Ther (Heidelb). 2018;8(4):571-9.

29. Barker J, Hoffmann M, Wozel G, et al. Efficacy and safety of infliximab vs. methotrexate in patients with moderate-to-severe plaque psoriasis: results of an open-label, active-controlled, randomized trial (RESTORE1). Br J Dermatol. 2011;165(5):1109-17.

30. Blauvelt A, Papp KA, Griffiths CE, et al. Efficacy and safety of guselkumab, an anti-interleukin-23 monoclonal antibody, compared with adalimumab for the continuous treatment of patients with moderate to severe psoriasis: results from the phase III, double-blinded, placebo- and active comparatorcontrolled VOYAGE 1 trial. J Am Acad Dermatol. 2017;76(3):405-17.

31. Blauvelt A, Prinz JC, Gottlieb AB, et al. Secukinumab administration by pre-filled syringe: efficacy, safety and usability results from a randomized controlled trial in psoriasis (FEATURE). Br J Dermatol. 2015;172(2):484-93.

32. Cai L, Gu J, Zheng J, et al. Efficacy and safety of adalimumab in Chinese patients with moderate-tosevere plaque psoriasis: results from a phase 3 , randomized, placebo-controlled, double-blind study. J Eur Acad Dermatol Venereol. 2017;31(1):89-95.

33. Caproni M, Antiga E, Melani L, Volpi W, Del Bianco E, Fabbri P. Serum levels of IL-17 and IL-22 are reduced by etanercept, but not by acitretin, in patients with psoriasis: a randomized-controlled trial. J Clin Immunol. 2009;29(2):210-4.

34. de Vries AC, Thio HB, de Kort WJ, et al. A prospective randomized controlled trial comparing infliximab and etanercept in patients with moderate-to-severe chronic plaque-type psoriasis: the Psoriasis Infliximab vs. Etanercept Comparison Evaluation (PIECE) study. $\mathrm{Br} \mathrm{J}$ Dermatol. 2017;176(3):624-33.

35. Flytstrom I, Stenberg B, Svensson A, Bergbrant IM. Methotrexate vs. ciclosporin in psoriasis: 
effectiveness, quality of life and safety. A randomized controlled trial. Br J Dermatol. 2008;158(1): 116-21.

36. Gelfand J, Joshi A, Shin D, et al. A trial to determine the effect of psoriasis treatment (adalimumab, phototherapy, and placebo) on cardiometabolic disease: The vascular inflammation in psoriasis (VIP) trial Abstract 393 (International Investigative Dermatology (IID) 2018 Meeting). J Investig Dermatol. 2018;138(5, Suppl):S67.

37. Gisondi P, Del Giglio M, Cotena C, Girolomoni G. Combining etanercept and acitretin in the therapy of chronic plaque psoriasis: a 24-week, randomized, controlled, investigator-blinded pilot trial. $\mathrm{Br} \mathrm{J}$ Dermatol. 2008;158(6):1345-9.

38. Gordon KB, Strober B, Lebwohl M, et al. Efficacy and safety of risankizumab in moderate-to-severe plaque psoriasis (UltIMMa-1 and UltIMMa-2): results from two double-blind, randomised, placebo-controlled and ustekinumab-controlled phase 3 trials. Lancet. 2018;392(10148):650-61.

39. Gordon K, Papp KA, Rice KC, Trivedi M, Collier DH, Kricorian G. Novel evaluation of Psoriasis Area and Severity Index (PASI) data: distribution of PASI improvements in a trial of etanercept for moderate to severe plaque psoriasis. Poster abstract. J Am Acad Dermatol. 2017;76(6, Suppl 1):181.

40. Gordon KB, Blauvelt A, Papp KA, et al. Phase 3 Trials of Ixekizumab in Moderate-to-Severe Plaque Psoriasis. N Engl J Med. 2016;375(4):345-56.

41. Gordon KB, Duffin KC, Bissonnette R, et al. A phase 2 trial of guselkumab versus adalimumab for plaque psoriasis. N Engl J Med. 2015;373(2):136-44.

42. Gordon KB, Langley RG, Leonardi C, et al. Clinical response to adalimumab treatment in patients with moderate to severe psoriasis: double-blind, randomized controlled trial and open-label extension study. J Am Acad Dermatol. 2006;55(4):598-606.

43. Gottlieb AB, Blauvelt A, Prinz JC, et al. Secukinumab self-administration by prefilled syringe maintains reduction of plaque psoriasis severity over 52 weeks: results of the FEATURE Trial. J Drugs Dermatol. 2016;15(10):1226-34.

44. Gottlieb AB, Blauvelt A, Thaci D, et al. Certolizumab pegol for the treatment of chronic plaque psoriasis: results through 48 weeks from 2 phase 3 , multicenter, randomized, double-blinded, placebo-controlled studies (CIMPASI-1 and CIMPASI-2). J Am Acad Dermatol. 2018;79(2):302-314e306.

45. Gottlieb AB, Evans R, Li S, et al. Infliximab induction therapy for patients with severe plaque-type psoriasis: a randomized, double-blind, placebo- controlled trial. J Am Acad Dermatol. 2004;51(4): 534-42.

46. Gottlieb AB, Leonardi C, Kerdel F, Mehlis S, Olds M, Williams DA. Efficacy and safety of briakinumab vs. etanercept and placebo in patients with moderate to severe chronic plaque psoriasis. Br J Dermatol. 2011;165(3):652-60.

47. Gottlieb AB, Matheson RT, Lowe N, et al. A randomized trial of etanercept as monotherapy for psoriasis. Arch Dermatol. 2003;139(12):1627-32 (discussion 1632).

48. Griffiths CE, Reich K, Lebwohl M, et al. Comparison of ixekizumab with etanercept or placebo in moderate-to-severe psoriasis (UNCOVER-2 and UNCOVER-3): results from two phase 3 randomised trials. Lancet. 2015;386(9993):541-51.

49. Griffiths CE, Strober BE, van de Kerkhof P, et al. Comparison of ustekinumab and etanercept for moderate-to-severe psoriasis. $\mathrm{N}$ Engl J Med. 2010;362(2):118-28.

50. Heydendael VM, Spuls PI, Opmeer BC, et al. Methotrexate versus cyclosporine in moderate-tosevere chronic plaque psoriasis. $\mathrm{N}$ Engl J Med. 2003;349(7):658-65.

51. Igarashi A, Kato T, Kato M, Song M, Nakagawa H, Japanese Ustekinumab Study G. Efficacy and safety of ustekinumab in Japanese patients with moderateto-severe plaque-type psoriasis: long-term results from a phase $2 / 3$ clinical trial. J Dermatol. 2012;39(3):242-52.

52. Langley RG, Elewski BE, Lebwohl M, et al. Secukinumab in plaque psoriasis-results of two phase 3 trials. N Engl J Med. 2014;371(4):326-38.

53. Lebwohl M, Blauvelt A, Paul C, et al. Certolizumab pegol for the treatment of chronic plaque psoriasis: Results through 48 weeks of a phase 3 , multicenter, randomized, double-blind, etanercept- and placebocontrolled study (CIMPACT). J Am Acad Dermatol. 2018;79(2):266-276.e265.

54. Lebwohl M, Strober B, Menter A, et al. Phase 3 studies comparing brodalumab with ustekinumab in psoriasis. N Engl J Med. 2015;373(14):1318-28.

55. Leonardi CL, Kimball AB, Papp KA, et al. Efficacy and safety of ustekinumab, a human interleukin$12 / 23$ monoclonal antibody, in patients with psoriasis: 76-week results from a randomised, doubleblind, placebo-controlled trial (PHOENIX 1). Lancet. 2008;371(9625):1665-74.

56. Leonardi CL, Powers JL, Matheson RT, et al. Etanercept as monotherapy in patients with psoriasis. N Engl J Med. 2003;349(21):2014-22. 
57. Meffert H, Brautigam M, Farber L, Weidinger G. Low-dose $(1.25 \mathrm{mg} / \mathrm{kg})$ cyclosporin A: treatment of psoriasis and investigation of the influence on lipid profile. Acta Derm Venereol. 1997;77(2):137-41.

58. Menter A, Feldman SR, Weinstein GD, et al. A randomized comparison of continuous vs. intermittent infliximab maintenance regimens over 1 year in the treatment of moderate-to-severe plaque psoriasis. J Am Acad Dermatol. 2007;56(1):31e31-15.

59. Menter A, Tyring SK, Gordon K, et al. Adalimumab therapy for moderate to severe psoriasis: a randomized, controlled phase III trial. J Am Acad Dermatol. 2008;58(1):106-15.

60. Mrowietz U, Kragballe $\mathrm{K}$, Reich $\mathrm{K}$, et al. An assessment of adalimumab efficacy in three Phase III clinical trials using the European Consensus Programme criteria for psoriasis treatment goals. Br J Dermatol. 2013;168(2):374-80.

61. Mrowietz U, Szepietowski JC, Loewe R, et al. Efficacy and safety of LAS41008 (dimethyl fumarate) in adults with moderate-to-severe chronic plaque psoriasis: a randomized, double-blind, Fumaderm ${ }^{\circledR}$ - and placebo-controlled trial (BRIDGE). Br J Dermatol. 2017;176(3):615-23.

62. Nakagawa H, Niiro H, Ootaki K, Japanese brodalumab study g. Brodalumab, a human anti-interleukin-17-receptor antibody in the treatment of Japanese patients with moderate-to-severe plaque psoriasis: efficacy and safety results from a phase II randomized controlled study. J Dermatol Sci. 2016;81(1):44-52.

63. Ohtsuki M, Kubo H, Morishima H, Goto R, Zheng R, Nakagawa H. Guselkumab, an anti-interleukin-23 monoclonal antibody, for the treatment of moderate to severe plaque-type psoriasis in Japanese patients: Efficacy and safety results from a phase 3, randomized, double-blind, placebo-controlled study. J Dermatol. 2018;45(9):1053-62.

64. Ohtsuki M, Okubo Y, Komine M, et al. Apremilast, an oral phosphodiesterase 4 inhibitor, in the treatment of Japanese patients with moderate to severe plaque psoriasis: Efficacy, safety and tolerability results from a phase $2 \mathrm{~b}$ randomized controlled trial. J Dermatol. 2017;44(8):873-84.

65. Paul C, Cather J, Gooderham M, et al. Efficacy and safety of apremilast, an oral phosphodiesterase 4 inhibitor, in patients with moderate-to-severe plaque psoriasis over 52 weeks: a phase III, randomized controlled trial (ESTEEM 2). $\mathrm{Br} \mathrm{J}$ Dermatol. 2015;173(6):1387-99.

66. Paul C, Lacour JP, Tedremets L, et al. Efficacy, safety and usability of secukinumab administration by autoinjector/pen in psoriasis: a randomized, controlled trial (JUNCTURE). J Eur Acad Dermatol Venereol. 2015;29(6):1082-90.

67. Reich K, Nestle FO, Papp K, et al. Infliximab induction and maintenance therapy for moderateto-severe psoriasis: a phase III, multicentre, doubleblind trial. Lancet. 2005;366(9494):1367-74.

68. Reich K, Nestle FO, Papp K, et al. Improvement in quality of life with infliximab induction and maintenance therapy in patients with moderate-tosevere psoriasis: a randomized controlled trial. Br J Dermatol. 2006;154(6):1161-8.

69. Reich K, Ortonne JP, Gottlieb AB, et al. Successful treatment of moderate to severe plaque psoriasis with the PEGylated Fab' certolizumab pegol: results of a phase II randomized, placebo-controlled trial with a re-treatment extension. $\mathrm{Br} \mathrm{J}$ Dermatol. 2012;167(1):180-90.

70. Reich K, Armstrong AW, Foley P, et al. Efficacy and safety of guselkumab, an anti-interleukin-23 monoclonal antibody, compared with adalimumab for the treatment of patients with moderate to severe psoriasis with randomized withdrawal and retreatment: Results from the phase III, double-blind, placebo- and active comparator-controlled VOYAGE 2 trial. J Am Acad Dermatol. 2017;76(3): 418-31.

71. Reich K, Gooderham M, Green L, et al. The efficacy and safety of apremilast, etanercept and placebo in patients with moderate-to-severe plaque psoriasis: 52-week results from a phase IIIb, randomized, placebo-controlled trial (LIBERATE). J Eur Acad Dermatol Venereol. 2017;31(3):507-17.

72. Reich K, Sullivan J, Arenberger P, et al. Effect of secukinumab on the clinical activity and disease burden of nail psoriasis: 32-week results from the randomized placebo-controlled TRANSFIGURE trial. Br J Dermatol. 2019;181(5):954-66.

73. Saurat JH, Stingl G, Dubertret L, et al. Efficacy and safety results from the randomized controlled comparative study of adalimumab vs. methotrexate vs. placebo in patients with psoriasis (CHAMPION). Br J Dermatol. 2008;158(3):558-66.

74. Stein Gold L, Bagel J, Lebwohl M, et al. Efficacy and safety of apremilast in systemic- and biologic-naive patients with moderate plaque psoriasis: 52-week results of UNVEIL. J Drugs Dermatol. 2018;17(2): 221-8.

75. Thaci D, Blauvelt A, Reich K, et al. Secukinumab is superior to ustekinumab in clearing skin of subjects with moderate to severe plaque psoriasis: CLEAR, a randomized controlled trial. J Am Acad Dermatol. 2015;73(3):400-9. 
76. Torii H, Nakagawa H, Japanese Infliximab Study Investigators. Infliximab monotherapy in Japanese patients with moderate-to-severe plaque psoriasis and psoriatic arthritis. A randomized, double-blind, placebo-controlled multicenter trial. J Dermatol Sci. 2010;59(1):40-9.

77. Tyring S, Gottlieb A, Papp K, et al. Etanercept and clinical outcomes, fatigue, and depression in psoriasis: double-blind placebo-controlled randomised phase III trial. Lancet. 2006;367(9504):29-35.

78. van de Kerkhof PC, Segaert S, Lahfa M, et al. Once weekly administration of etanercept $50 \mathrm{mg}$ is efficacious and well tolerated in patients with moderate-to-severe plaque psoriasis: a randomized controlled trial with open-label extension. $\mathrm{Br} \mathrm{J}$ Dermatol. 2008;159(5):1177-85.

79. von Stebut E, Reich K, Thaci D, et al. Impact of secukinumab on endothelial dysfunction and other cardiovascular disease parameters in psoriasis patients over 52 weeks. J Invest Dermatol. 2019;139(5):1054-62.

80. Yang HZ, Wang K, Jin HZ, et al. Infliximab monotherapy for Chinese patients with moderate to severe plaque psoriasis: a randomized, doubleblind, placebo-controlled multicenter trial. Chin Med J (Engl). 2012;125(11):1845-51.

81. Papp K, Cather JC, Rosoph L, et al. Efficacy of apremilast in the treatment of moderate to severe psoriasis: a randomised controlled trial. Lancet. 2012;380(9843):738-46.

82. Papp K, Menter A, Strober B, et al. Efficacy and safety of brodalumab in subpopulations of patients with difficult-to-treat moderate-to-severe plaque psoriasis. J Am Acad Dermatol. 2015;72(3):436-439. e431.

83. Papp K, Reich K, Leonardi CL, et al. Apremilast, an oral phosphodiesterase 4 (PDE4) inhibitor, in patients with moderate to severe plaque psoriasis: results of a phase III, randomized, controlled trial (Efficacy and Safety Trial Evaluating the Effects of Apremilast in Psoriasis [ESTEEM] 1). J Am Acad Dermatol. 2015;73(1):37-49.

84. Papp KA, Leonardi C, Menter A, et al. Brodalumab, an anti-interleukin-17-receptor antibody for psoriasis. N Engl J Med. 2012;366(13):1181-9.

85. Papp KA, Leonardi CL, Blauvelt A, et al. Ixekizumab treatment for psoriasis: integrated efficacy analysis of three double-blinded, controlled studies (UNCOVER-1, UNCOVER-2, UNCOVER-3). Br J Dermatol. 2018;178(3):674-81.

86. Papp KA, Reich K, Paul C, et al. A prospective phase III, randomized, double-blind, placebo-controlled study of brodalumab in patients with moderate-tosevere plaque psoriasis. Br J Dermatol. 2016;175(2): 273-86.

87. Papp KA, Tyring S, Lahfa M, et al. A global phase III randomized controlled trial of etanercept in psoriasis: safety, efficacy, and effect of dose reduction. Br J Dermatol. 2005;152(6):1304-12.

88. Spiegelhalter D, Best NG, Carlin BP, Van Der Linde A. Bayesian measures of model complexity and fit. J R Stat Soc Stat Methodol Ser B. 2002;64(4): 583-639.

89. Dias S, Welton NJ, Sutton AJ, Caldwell DM, Lu G, Ades AE. NICE DSU Technical Support Document 4: inconsistency in networks of evidence based on randomised controlled trials. 2011. http://nicedsu. org.uk/wp-content/uploads/2016/03/TSD4-

Inconsistency.final_.15April2014.pdf. Accessed 2 Nov 2017.

90. Armstrong AW, Betts KA, Signorovitch JE, et al. Number needed to treat and costs per responder among biologic treatments for moderate-to-severe psoriasis: a network meta-analysis. Curr Med Res Opin. 2018;34(7):1325-33.

91. Bai F, Li GG, Liu Q, Niu X, Li R, Ma H. Short-term efficacy and safety of IL-17, IL-12/23, and IL-23 inhibitors brodalumab, secukinumab, ixekizumab, ustekinumab, guselkumab, tildrakizumab, and risankizumab for the treatment of moderate to severe plaque psoriasis: a systematic review and network meta-analysis of randomized controlled trials. J Immunol Res. 2019;2019:2546161.

92. Geng W, Zhao J, Fu J, Zhang H, Qiao S. Efficacy of several biological therapies for treating moderate to severe psoriasis: a network meta-analysis. Exp Ther Med. 2018;16(6):5085-95.

93. Gomez-Garcia F, Epstein D, Isla-Tejera B, Lorente A, Velez Garcia-Nieto A, Ruano J. Short-term efficacy and safety of new biological agents targeting the interleukin-23-T helper 17 pathway for moderateto-severe plaque psoriasis: a systematic review and network meta-analysis. Br J Dermatol. 2017;176(3): 594-603.

94. Gupta AK, Daigle D, Lyons DC. Network metaanalysis of treatments for chronic plaque psoriasis in Canada. J Cutan Med Surg. 2014;18(6):371-8.

95. Sawyer LM, Malottki K, Sabry-Grant C, et al. Assessing the relative efficacy of interleukin-17 and interleukin-23 targeted treatments for moderate-tosevere plaque psoriasis: a systematic review and network meta-analysis of PASI response. PLoS ONE. 2019;14(8):e0220868. 
96. Sbidian E, Chaimani A, Afach S, et al. Systemic pharmacological treatments for chronic plaque psoriasis: a network meta-analysis. Cochrane Database Syst Rev. 2020;1:CD011535.

97. Tada Y, Watanabe R, Noma H, Kanai Y, Nomura T, Kaneko K. Short-term effectiveness of biologics in patients with moderate-to-severe plaque psoriasis: a systematic review and network meta-analysis. J Dermatol Sci. 2020;99(1):53-61.

98. Wright E, Yasmeen N, Malottki K, et al. Assessing the quality and coherence of network meta-analyses of biologics in plaque psoriasis: what does all this evidence synthesis tell us? Dermatology and therapy. 2021;11(1):181-220.

99. National Institute for Health and Care Excellence (NICE). TA537: Ixekizumab for treating active psoriatic arthritis after inadequate response to DMARDs. 2018. https://www.nice.org.uk/guidance/ ta537. Accessed 3 Feb 2020.

100. Papp KA, Gordon K, Langley R, et al. Impact of previous biologic use on the efficacy and safety of brodalumab and ustekinumab in patients with moderate-to-severe plaque psoriasis: integrated analysis of the randomized controlled trials AMAGINE-2 and AMAGINE-3. Br J Dermatol. 2018;179(2):320-8.

101. Antiga E, Volpi W, Chiarini C, et al. The role of etanercept on the expression of markers of $\mathrm{T}$ helper 17 cells and their precursors in skin lesions of patients with psoriasis vulgaris. Int J Immunopathol Pharmacol. 2010;23(3):767-74.

102. Bagel J, Lynde C, Tyring S, Kricorian G, Shi Y, Klekotka P. Moderate to severe plaque psoriasis with scalp involvement: a randomized, double-blind, placebo-controlled study of etanercept. J Am Acad Dermatol. 2012;67(1):86-92.

103. Chaudhari U, Romano P, Mulcahy LD, Dooley LT, Baker DG, Gottlieb AB. Efficacy and safety of infliximab monotherapy for plaque-type psoriasis: a randomised trial. Lancet. 2001;357(9271):1842-7.

104. Reich K, Armstrong A, Blauvelt A, et al. Guselkumab demonstrates superior long-term responses compared with secukinumab in the treatment of moderate to severe plaque psoriasis: Results from the ECLIPSE trial. J Eur Acad Dermatol Venerol. 2019;33(Suppl. 3):5.

105. Goldminz AM, Suarez-Farinas M, Wang AC, Dumont N, Krueger JG, Gottlieb AB. CCL20 and IL22 messenger RNA expression after adalimumab vs methotrexate treatment of psoriasis: a randomized clinical trial. JAMA Dermatol. 2015;151(8): 837-46.

106. Reich K, Pinter A, Lacour JP, et al. Comparison of ixekizumab with ustekinumab in moderate-to-severe psoriasis: 24-week results from IXORA-S, a phase III study. Br J Dermatol. 2017;177(4):1014-23.

107. Reich K, Pinter A, Leutz A, et al. A randomized, open-label comparison of ixekizumab vs. methotrexate in patients with moderate-to-severe plaque-type psoriasis naive to systemic therapy: interim analysis of week 12 findings. Br J Dermatol. 2017;177 (Suppl. 1):61

108. Menter A, Gordon KB, Leonardi CL, Gu Y, Goldblum OM. Efficacy and safety of adalimumab across subgroups of patients with moderate to severe psoriasis. J Am Acad Dermatol. 2010;63(3):448-56.

109. Rich P, Sigurgeirsson B, Thaci D, et al. Secukinumab induction and maintenance therapy in moderateto-severe plaque psoriasis: a randomized, doubleblind, placebo-controlled, phase II regimen-finding study. Br J Dermatol. 2013;168(2):402-11.

110. Gottlieb AB, Lacour JP, Korman N, et al. Treatment outcomes with ixekizumab in patients with moderate-to-severe psoriasis who have or have not received prior biological therapies: an integrated analysis of two Phase III randomized studies. J Eur Acad Dermatol Venereol. 2017;31(4):679-85.

111. Kemeny L, Berggren L, Dossenbach M, Dutronc Y, Paul C. Efficacy and safety of ixekizumab in patients with plaque psoriasis across different degrees of disease severity: results from UNCOVER-2 and UNCOVER-3. J Dermatolog Treat. 2019;30(1): 19-26. 